Review article

\title{
New insights into the dynamic development of the cerebral cortex in childhood and adolescence: Integrating macro- and microstructural MRI findings
}

\author{
Linn B. Norbom ${ }^{\mathrm{a}, \mathrm{b}, \mathrm{c}, * \text {, Lia Ferschmann }}{ }^{\mathrm{b}}$, Nadine Parker ${ }^{\mathrm{d}}$, Ingrid Agartz ${ }^{\mathrm{a}, \mathrm{c}, \mathrm{e}}$,

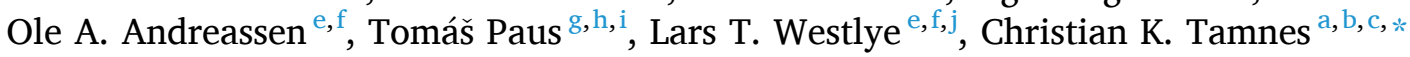 \\ ${ }^{\text {a }}$ NORMENT, Institute of Clinical Medicine, University of Oslo, Norway \\ ${ }^{\mathrm{b}}$ PROMENTA Research Center, Department of Psychology, University of Oslo, Norway \\ ${ }^{\mathrm{c}}$ Department of Psychiatric Research, Diakonhjemmet Hospital, Oslo, Norway \\ ${ }^{\mathrm{d}}$ Institute of Medical Science, University of Toronto, Ontario, Canada \\ ${ }^{\mathrm{e}}$ K.G Jebsen Center for Neurodevelopmental Disorders, University of Oslo, Norway \\ ${ }^{\mathrm{f}}$ NORMENT, Division of Mental Health and Addiction, Oslo University Hospital \& Institute of Clinical Medicine, University of Oslo, Norway \\ ${ }^{8}$ ECOGENE-21, Chicoutimi, Quebec, Canada \\ ${ }^{\mathrm{h}}$ Department of Psychology and Psychiatry, University of Toronto, Ontario, Canada \\ ${ }^{\mathrm{i}}$ Department of Psychiatry and Centre hospitalier universitaire Sainte-Justine, University of Montreal, Canada \\ ${ }^{\mathrm{j}}$ Department of Psychology, University of Oslo, Norway
}

\section{A R T I C L E I N F O}

\section{Keywords:}

Adolescence

Cerebral cortex

Childhood

Gene expression

Signal intensity

Structure

\begin{abstract}
A B S T R A C T
Through dynamic transactional processes between genetic and environmental factors, childhood and adolescence involve reorganization and optimization of the cerebral cortex. The cortex and its development plays a crucial role for prototypical human cognitive abilities. At the same time, many common mental disorders appear during these critical phases of neurodevelopment. Magnetic resonance imaging (MRI) can indirectly capture several multifaceted changes of cortical macro- and microstructure, of high relevance to further our understanding of the neural foundation of cognition and mental health. Great progress has been made recently in mapping the typical development of cortical morphology. Moreover, newer less explored MRI signal intensity and specialized quantitative T2 measures have been applied to assess microstructural cortical development. We review recent findings of typical postnatal macro- and microstructural development of the cerebral cortex from early childhood to young adulthood. We cover studies of cortical volume, thickness, area, gyrification, T1weighted $(\mathrm{T} 1 \mathrm{w})$ tissue contrasts such a grey/white matter contrast, T1w/T2w ratio, magnetization transfer and myelin water fraction. Finally, we integrate imaging studies with cortical gene expression findings to further our understanding of the underlying neurobiology of the developmental changes, bridging the gap between ex vivo histological- and in vivo MRI studies.
\end{abstract}

\section{Introduction}

Childhood and adolescence represent remarkable periods of change. Early childhood involves extensive physical changes, major improvements in sensorimotor skills, and cognitive evolutions of self-awareness and language acquisition (Colson and Dworkin, 1997; McMurray, 2007; Rochat, 2003). Social bonding is another important childhood landmark, with play-time fostering several aspects of this development (Ginsburg et al., 2007). Adolescence, signifying the transitional period between childhood and adulthood, brings forth a novel set of advancements. These include pubertal bodily and hormonal alterations, further development of complex and abstract thinking, heightened emotional reactivity, increases in certain risk-taking behaviors, an urge for independence, as well as major changes in socio-cultural roles and interpersonal relationships (Blakemore and Mills, 2014; Choudhury, 2010; Marshall and Tanner, 1970, 1969; Piaget and Cook, 1952; Silvers et al., 2012; Steinberg, 2008).

Childhood and adolescence are also central periods for brain

\footnotetext{
* Corresponding authors at: NORMENT, Institute of Clinical Medicine, University of Oslo, Norway.

E-mail addresses: 1.c.b.norbom@psykologi.uio.no (L.B. Norbom), c.k.tamnes@psykologi.uio.no (C.K. Tamnes).
} 
reorganization and optimization (Blakemore, 2012; Brown and Jernigan, 2012; Lebel and Deoni, 2018). The cerebral cortex is a principal neural structure for our cognitive abilities (Harris and Shepherd, 2015; Rakic, 2009) and its spatiotemporal development is paralleled by qualitative and quantitative cognitive strides (Akshoomoff et al., 2014; Casey et al., 2005). Studying cortical maturation is therefore a natural step to understand cognitive development. Compared with closely related non-human primates, certain features of human cortical development appear temporally extended (Hawrylycz et al., 2012; Miller et al., 2012). One could speculate that this protracted development is advantageous, allowing for environmental experiences to foster adaptation and learning, while at the same time coming with certain costs. Indeed, childhood and adolescence are periods when many common mental disorders emerge (Kessler et al., 2005; Paus et al., 2008). The dynamic interplay of multiple genetic and environmental risk factors likely precipitates deviant pre- and postnatal neurodevelopment, and in turn emerging mental health problems (Paus et al., 2008). Put differently, most common mental disorders are today understood as neurodevelopmental in nature, and investigating brain development and its individual variation is consequently of high relevance.

Magnetic resonance imaging (MRI) can indirectly measure multifaceted properties and developmental processes of the cerebral cortex, while being in vivo and noninvasive (Lerch et al., 2017). Macrostructural or morphometric quantifications include cortical volume, its subcomponents, namely thickness and surface area, as well as cortical gyrification indices (Desikan et al., 2006; Fischl, 2012; Fischl and Dale, 2000; Winkler et al., 2012). Beyond morphometric changes, newer less explored microstructural MRI measures are sensitive to "the brightness" or intensity variation in cerebral tissues, which is presumed to be of neurobiological relevance (Glasser and Van Essen, 2011; Salat et al., 2009; Westlye et al., 2010). It has also been shown that more specialized microstructural assessments that are sensitive to rapid $\mathrm{T} 2$ signal decay (Alonso-Ortiz et al., 2015) can successfully be applied to study cerebral cortical development.

To further our understanding of cognitive development and neurodevelopmental psychopathology, it is essential to determine first the characteristics of and variation in macro- and microstructural brain development. Recent studies have revised our knowledge of the developmental trajectories of cortical morphology (as discussed e.g. in (Mills and Tamnes, 2014; Walhovd et al., 2016a), yet dated descriptions of cortical thickness and volume development are still prevalent in the broader literature. Additionally, although reflecting partly separate underlying neurobiological and polygenic underpinnings (Panizzon et al., 2012; Patel et al., 2020), there are no previous literature reviews covering cortical developmental changes as assessed using signal intensity measures, magnetization transfer (MT) or myelin water fraction (MWF). Further, cortical structure and developmental trajectories could differ to some extent between males and females (Kaczkurkin et al., 2019; Paus, 2010). Yet, beyond the consistent finding of larger brain volumes and cortical surface areas in males, results on sex differences in cortical development are difficult to reconcile (Jahanshad and Thompson, 2017; Paus et al., 2017; Wierenga et al., 2018). Another vital, but challenging task is to link developmental changes in morphology and microstructural measures to specific underlying neurobiological processes.

The objective of the current review is to summarize and discuss contemporary MRI research on typical development of the human cerebral cortical from early childhood to young adulthood. After a description of the anatomical and cellular architecture of the cortex, we review recent macro- and microstructural MRI findings across a range of imaging tools, the possible underlying neurobiological processes, and how different features of cortical development can be integrated. Finally, we will consider recent studies that have used transcriptomics to probe the neurobiological events underlying the development of the cerebral cortex. Of note, cortical developmental processes in childhood and adolescence are oftentimes continuations of processes beginning before birth or in infancy. Research on fetal and neonatal brain development is not, however, covered in the current review due to differences in the scale and scope of the changes and in neuroimaging methods, but is reviewed elsewhere (Batalle et al., 2018; Lebel and Deoni, 2018; Makropoulos et al., 2018; Thomason, 2020).

\section{The architecture of the human cerebral cortex}

The cerebral cortex, constituting the outermost part of the brain, characteristically resembles a highly folded sheath, with peaks and valleys termed gyri and sulci, respectively (Destrieux et al., 2010). It consists of several cortical layers (six in the neocortex), with an average thickness of about $2.5 \mathrm{~mm}$ (Brodmann, 1909; Palomero-Gallagher and Zilles, 2019). The cerebral cortex contains tens of billions of brain cells (Pelvig et al., 2008), including pyramidal- and interneurons neatly packed and organized column-wise for effective long-range and local signal transmission, respectively (Mountcastle, 1995; Rakic, 2009, 1995). The cortex also comprises dendrites, glial cells, and myelinated and unmyelinated axons (Nieuwenhuys, 2013). The specific cellular composition and distribution vary greatly depending on the cortical region and layer (Brodmann, 1909; Palomero-Gallagher and Zilles, 2019), as does the layers functional role (Bastos et al., 2012) and structural connectivity (Rockland, 2015). There is, nevertheless, generally a profusion of neuronal cell bodies within superior cortical layers, and myelinated axons in deeper cortical layers. This is in part as subjacent white matter myelin penetrates the cortical neuropil (Nieuwenhuys, 2013), while many other cortico-cortical axons never leave, originating and terminating within the cortex (Paus et al., 2014).

The advancement of staining techniques in the late 1800 s allowed for histological subdivisions of the full cortex (Palomero-Gallagher and Zilles, 2019). These atlases, still of high relevance today, are based on "cytoarchitecture", meaning differences in cell types and the density of cell bodies, or "myeloarchitecture", meaning the density and arrangements of myelinated fibers. The Brodmann (Brodmann, 1909) and Vogt (Nieuwenhuys, 2013) monographies are fine examples of such atlases. Using advanced MRI analysis programs, the cortex can be divided into finely grained sections using, for instance, markers of myelination, structural connectivity with other brain regions, functional specialization (Fan et al., 2016; Glasser et al., 2016; Yeo et al., 2011) or genetic influences (Chen et al., 2013, 2012). Another window into cortical organization and function is through its spatiotemporal maturational patterns in childhood and adolescence.

\section{The morphological development of the cerebral cortex}

Human corticogenesis starts early in the fetal period and involves a cascade of events, including the emergence of transient layers (Bystron et al., 2008). Neurons originating in the ventricular zone migrate to form the preplate, then, when the cortical plate is formed, the preplate separates into the marginal zone and the subplate (Chan et al., 2002; Miquelajáuregui and Varela-Echavarría, 2008). Despite later transformation or disappearance of the transient layers, cells from these compartments play central roles in cortical development and organization (Kostović, 2020; Molnár et al., 2020; Vasung et al., 2020).

Cortical macrostructure, or morphology, refers to the gross features of the cerebral cortex, such as size and shape. MRI studies of the morphology of the cerebral cortex and its postnatal development typically assess volume, thickness, surface area or folding, the latter also known as degree of gyrification (Hogstrom et al., 2013). A growing number of neuroimaging studies collecting or combining data in a large number of individuals (e.g. (Frangou et al., 2020)), also longitudinally (e.g. (Tamnes et al., 2017; Vidal-Pineiro et al., 2020), have provided new insights into typical age-related differences and developmental trajectories of the different cortical components.

Generally, cortical morphology show rapid changes early in life (Gilmore et al., 2018), followed by protracted changes throughout 
childhood and adolescence (Tamnes et al., 2017; Vidal-Pineiro et al., 2020; Vijayakumar et al., 2016). Development of cortical morphology is characterized by nonlinear changes, i.e. there may be periods of greater change, and by regionally specific patterns. Combined, these spatiotemporal patterns appear to progress in a back-to-front direction, and with sensorimotor regions maturing earlier than association cortices (Gogtay et al., 2004; Tamnes et al., 2013). The sequence of cortical maturation corresponds with functional maturation, where more basic and sensory functions mature earlier than higher-order cognitive functions, including social cognitive processes (Andrews et al., 2021; Gogtay et al., 2004). Although cortical morphology and its development have been related to sociodemographic variables, behavior, and cognition in healthy and clinical populations (e.g. (Alnæs et al., 2020; Chung et al., 2017; Ehrlich et al., 2012; Farah, 2017; Hooker et al., 2011; Schnack et al., 2015), the relationships are complex and typically small (Dick et al., 2020; Paulus and Thompson, 2019; Walhovd et al., 2014).

Cortical volume can be defined as the product of thickness and surface area (Panizzon et al., 2009). Although novel methods for their joint analysis are available and appropriate in several cases (Doan et al., 2017; Winkler et al., 2018), it has become common to consider these measures separately. This is because they seem to be driven by biologically distinct processes (Rakic, 1988), may show differential sensitivity to variation in cognitive abilities and mental disorders (Rimol et al., 2012; Schmaal et al., 2017; Schnack et al., 2015; Vuoksimaa et al., 2016), and have been found to have distinct sets of genetic influences, as inferred from twin and family studies (Panizzon et al., 2009; Winkler et al., 2010), and weak genetic correlations (Hofer et al., 2020). Although recent findings suggest a significant polygenic overlap between cortical thickness and surface area, the details of the molecular architecture underlying the two cortical features are quite different (Grasby et al., 2020; van der Meer et al., 2020). Importantly, cortical thickness and surface area also follow different developmental trajectories (Lyall et al., 2015; Tamnes et al., 2017; Wierenga et al., 2014) (see Fig. 1).

This section will provide an overview of morphological cerebral cortical development in childhood and adolescence by reviewing studies of gray matter volume, thickness, surface area, and gyrification. Given vast support for the distinctness of the two main components of volume, we discuss thickness and surface area in greater detail. Sex differences and biological factors underlying these developmental changes will also be discussed.
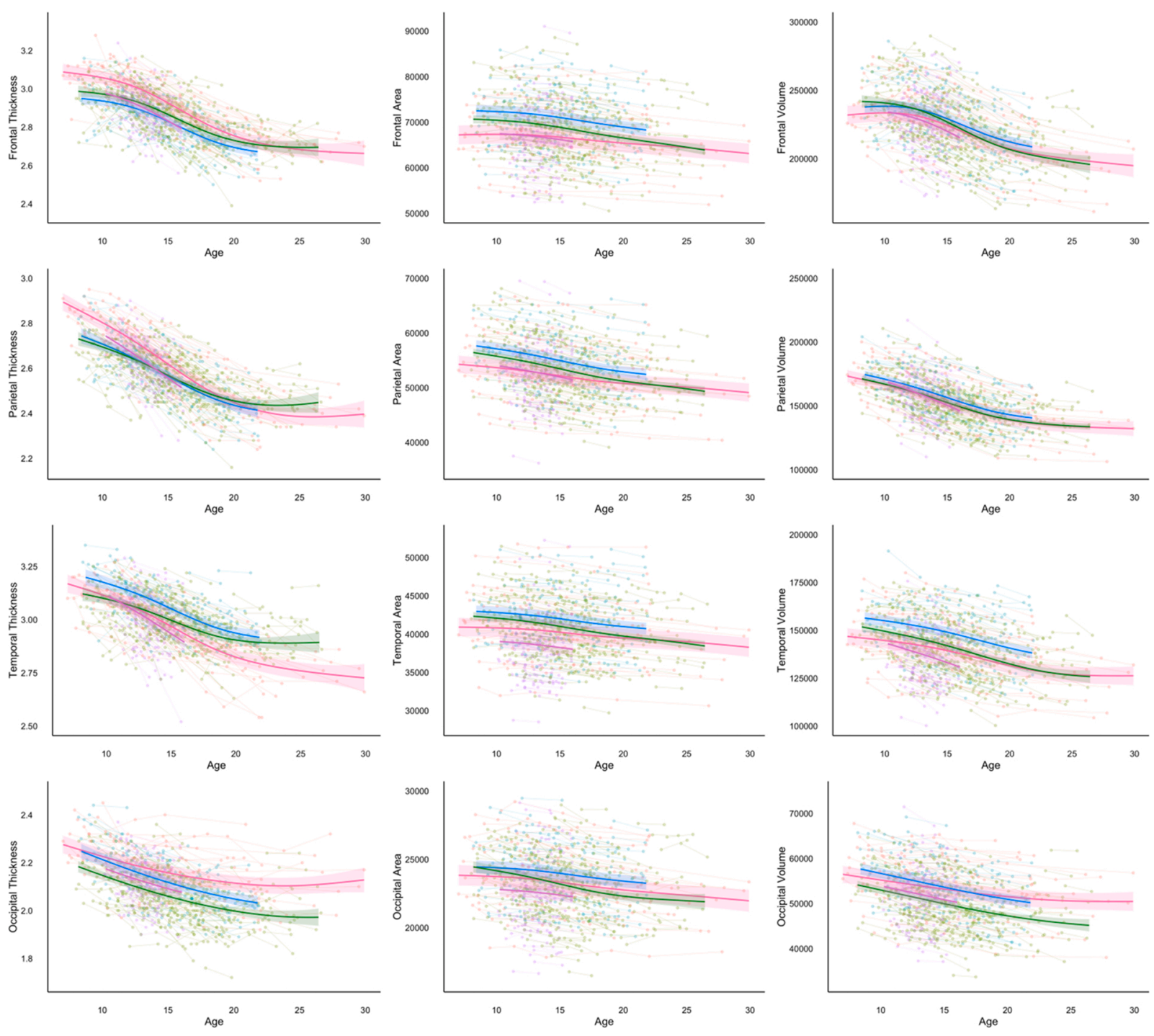

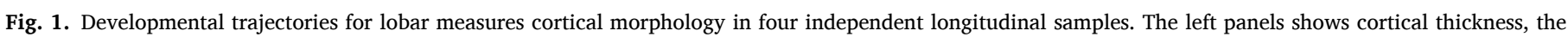

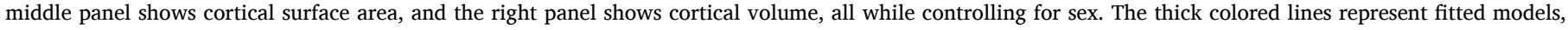
while the lighter colored areas correspond to the $95 \%$ confidence intervals. The figure is adapted from Tamnes et al. (2017). 


\subsection{Volume}

Cortical gray matter volume is typically estimated either using volume-based representations, such as voxel-based morphometry (VBM), or surface-based representations where volume is defined as the amount of tissue between the pial and the white surface (Winkler et al., 2018). Gilmore et al. (2012) examined development of cortical volume in 72 infants shortly after birth and at ages 1 and 2 years, and found substantially larger growth during the first compared with the second year, with relatively faster growth in association areas as compared with primary motor and sensory areas during the first two years of life. Beyond the infant and toddler periods, early studies assessing cortical volume development in youth reported an inverted U-shaped trajectory, with peak regional volumes in late childhood or early adolescence (e.g. (Giedd et al., 1999; Gogtay et al., 2004; Lenroot et al., 2007; Raznahan et al., 2011b)). More recent studies have not, however, identified peaks in overall cortical volume during these periods. For example, a study using four independent longitudinal samples with a total of $852 \mathrm{MRI}$ scans from 391 participants aged 8-30 years (Mills et al., 2016) and a study with 202 scans from 135 individuals aged 7-23 years (Wierenga et al., 2014) both found monotonic non-linear decreases, indicating that cortical volume starts decreasing substantially earlier than previously reported. Developmental "peaks" have been identified in a few cortical regions, including anterior temporal cortices (Mills et al., 2016) and parts of the frontal cortex (Wierenga et al., 2014), but these are likely only exceptions from the general pattern of cortical volume development.

In terms of sex differences, studies converge on larger volumes in males (vs. females) examined at both gross and regional level (Kaczkurkin et al., 2019; Lenroot et al., 2007; Mills et al., 2014; Raznahan et al., 2011b; Vijayakumar et al., 2016; Wierenga et al., 2014). Although inconsistencies exist regarding age by sex interactions on cortical volume, studies indicate that a few selected cortical regions may show different developmental trajectories in girls and boys (Paus et al., 2010; Vijayakumar et al., 2016; Wierenga et al., 2014).

\subsection{Thickness}

The influential radial unit hypothesis of cortical development posits that the three-dimensional architecture of the cerebral cortex can be traced back to the two-dimensional information of the proliferative units located in the ventricular zone; the site of origin in the ventricular zone gives information on $\mathrm{X}$ and $\mathrm{Y}$ axis of the cells, while $\mathrm{Z}$-axis is determined by the time of their origin (Rakic, 1995, 1988). Cohorts of vertically arranged neurons, that share the same birthplace in the ventricular zone, migrate radially to the cerebral cortex. By this account, the thickness of the human cerebral cortex is principally determined by the number of cell divisions within proliferative units in the ventricular zone (Rakic, 1988). Cortical thickness shows considerable regional variation, ranging between 1 and $4.5 \mathrm{~mm}$ (Fischl and Dale, 2000). In MRI, a common method to assess cortical thickness is to use T1-weighted images to create models of the white and pial surfaces before calculating thickness as the shortest vertex-wise distance between these (Fischl and Dale, 2000).

Longitudinal MRI studies have found that cortical thickness increases during the first years of life, and especially during the first as compared with the second year (Li et al., 2015; Lyall et al., 2015). In many regions, cortical thickness also appears to peak between the first and second year, as demonstrated by Wang et al. (2019) in 43 infants aged 0-2 years and scanned up to 7 times, and by Li et al. (2015) in a sample of 73 infants aged 0-2 years with 219 scans.

After this initial thickening, current longitudinal studies, some of which include children from 4 years old, report monotonic thinning in most cortical regions from childhood to adulthood (Ducharme et al., 2016; Fjell et al., 2015; Mills et al., 2014; Vidal-Pineiro et al., 2020; Vijayakumar et al., 2016; Wierenga et al., 2014). Of note, and similar to the discrepancy regarding cortical volume development, this is in contrast to some earlier pioneer longitudinal studies that reported peaks in thickness in late childhood or early adolescence (Raznahan et al., 2011ab; Shaw et al., 2007, 2008) (but see (Sowell et al., 2004; Tamnes et al., 2010)). Possible reasons for these discrepancies have been discussed elsewhere (Mills and Tamnes, 2014; Walhovd et al., 2016a) and include sample differences, image acquisition or processing differences, including different scanners, sequences and analysis tools, effects of variables such as head motion, and differences in statistical analyses and curve fitting. Generally, based on methodological advances and increased concern for data quality and focus on the importance of data quality assurance (e.g. (Alexander-Bloch et al., 2016; Ducharme et al., 2016; Gilmore et al., 2021; Rosen et al., 2018)), we believe that the results from studies from recent years that indicate peaks in cortical thickness during infancy or early childhood, followed by monotonic decreases in mid- and late childhood, adolescence and beyond are most likely to be true. As emphasized by Walhovd et al. (2016a), however, MRI-derived measures of cortical development are merely our best current approximations and do not directly reflect brain anatomy.

The apparent cortical thinning in childhood and adolescence also shows some spatiotemporal variation. For example, Zhou et al. (2015) scanned 90 individuals aged 5-32 years at two time-points and found slight acceleration in thinning during adolescence as compared with both childhood and young adulthood. In a study with four longitudinal samples with in total 854 scans from 388 participants 7-29 years old, Tamnes and colleagues (2017) found that the parietal lobe showed the largest annual decrease in cortical thickness, while the occipital lobe consistently showed the smallest decrease. Overall, studies of cortical thickness suggest a maturational posterior-to-anterior and/or sensory-to-association cortices temporal gradient (Walhovd et al., 2016a).

Regarding sex differences, a cross-sectional study of 805 two week old neonates did not find sex effects on average cortical thickness (Jha et al., 2019). Similarly, a cross-sectional study by Gennatas et al. (2017) found no differences between girls and boys in total cortical thickness in 1189 individuals aged $8-23$ years. In a recent large scale cross-sectional lifespan study with 17,075 individuals, the estimated age-related slopes of cortical thickness were not different within the subsample of young females and males aged 3-29 years (Frangou et al., 2020). Many longitudinal studies similarly report no or only limited sex differences in the developmental trajectories for cortical thickness (Mills et al., 2014; Raznahan et al., 2011b; Vijayakumar et al., 2016). There are some exceptions however (Ducharme et al., 2016; Mutlu et al., 2013; Paus et al., 2017; Wong et al., 2018), but the region specific patterns of thickness change are not consistent across studies.

To conclude, beyond the first two years of life, current large-scale and longitudinal studies suggest monotonic apparent cortical thinning in youth development, with some spatiotemporal variation in rate. Girls and boys generally show similar overall cortical thickness and thinning, but likely with some differences in the pace of thinning during specific developmental periods.

\subsubsection{Neurobiological processes underlying thickness development}

From infancy to young adulthood, the MRI-observed changes in cortical thickness are thought to reflect different processes depending on developmental stage and likely to some extent cortical region. The radial unit hypothesis posits that cortical thickness is determined by the number of cell divisions within proliferative units in the ventricular zone (Rakic, 1988). Neurogenesis and neuronal migration are, however, largely concluded by the end of the first postnatal week (Hill et al., 2010; Rakic, 2009). The increases in cortical thickness during the first years of life (Li et al., 2015; Lyall et al., 2015) are thus likely the result of rapid increases in dendritic complexity, myelination, synaptogenesis, glial proliferation and axonal elongation (Huttenlocher and Dabholkar, 1997; Koenderink et al., 1994; Koenderink and Uylings, 1995; Mrzljak et al., 1991; Petanjek et al., 2011; Rakic et al., 1994). During the early 
postnatal period, cortical thickness may also be impacted by the anatomical changes related to the dissolution of the subplate (Kostović, 2020; Marx et al., 2015; Sedmak and Judaš, 2021).

The two main candidate processes that underlie MRI-observed cortical thinning during childhood and adolescence focus on reorganization of dendritic arbour or pericortical myelination, while mechanical forces that alter cortical morphology have also been considered (Natu et al., 2019; Patel et al., 2019; Paus et al., 2008). Post-mortem histological studies have demonstrated increases in synaptic density in infancy, followed by a gradual decrease in synaptic and neural density through adolescence (Huttenlocher, 1979). Similarly, Petanjek et al. (2008) demonstrated, in their investigations of basal dendrites of pyramidal neurons, length related-, synapse number-, and dendritic spine overgrowth in childhood and early adolescence, followed by decreases in later adolescence. Additionally, emerging evidence suggest that microglia, the brain's resident immune cells, plays a role in monitoring synaptic function and in synaptic maturation and elimination (Paolicelli et al., 2011). However, developmental reductions in cortical thickness observed in MRI studies cannot be explained by small-scale changes at the synapse level (Bourgeois and Rakic, 1993; Paus et al., 2008). Instead, remodeling of dendritic arbour may be accompanied by reductions in the number of cortical glial cells, which may together explain some of the observed cortical thinning.

Myelination, the process of wrapping axons in a lipid rich sheath, is the second proposed mechanism that may explain the observed cortical thinning in MRI studies (Sowell et al., 2004). Myelin membranes contribute to the speed, reliability and frequency of information transfer and also provides structural support (Miller et al., 2012; Wake et al., 2011). Intracortical myelin content increases from early childhood in a general posterior to anterior fashion (Yakovlev and Lecours, 1967), but with additional regional specificity, as certain higher order regions continue to mature well into adulthood (Ritchie et al., 2018a; Williamson and Lyons, 2018). T1w voxel intensities increase in part as a function of increasing myelin content. Therefore, deep myelinated cortical layers could be misclassified by imaging software as white matter, thereby shifting the grey/white boundary outward (Norbom et al., 2020b). This would appear as cortical thinning, without necessarily implying actual loss of tissue (Natu et al., 2019; Sowell et al., 2004). Several studies support the notion of increased intracortical myelination explaining at least a portion of MRI-based cortical thinning (Natu et al., 2019; Whitaker et al., 2016), while other studies suggest that relations are likely more complex (Croteau-Chonka et al., 2016). Finally, mechanical changes that occur during development could also contribute to a thinner adult cortex (Hogstrom et al., 2013), although this view is challenged by findings of surface area remaining relatively stable from a young age, while cortical thinning continues across the lifespan (Amlien et al., 2016; Fjell et al., 2015). Importantly, proposed mechanisms of MRI-based developmental cortical thinning are not mutually exclusive, and could all contribute to a different extent, depending on developmental stage.

\subsection{Surface area}

According to the radial unit hypothesis, cortical surface area is principally determined by the number of contributing proliferative units (Rakic, 1988). In MRI studies, surface area is modelled based on the white surface, the pial surface or at times an average of the two called the "midthickness" (Fischl et al., 1999a, 1999b). Although methodological variations exist (Winkler et al., 2018), surface area is commonly estimated by assessing how much local distortion is needed to fit an individual brain to a standard template or atlas, resulting in a point-by-point expansion and contraction map (Fischl et al., 1999a; Hogstrom et al., 2013).

One of the few longitudinal studies of infants and toddlers (Li et al., 2013) demonstrated that during the first and second year postnatally, cortical surface area increases on average $80 \%$ and $20 \%$, respectively.
During the first year, regions heavily involved in sensory processing expand the most, while regions involved in higher order functioning greatly expand during the second year. Studies covering childhood, adolescence and young adulthood suggest that surface area in most regions continues to expand somewhat, reaching peaks in late childhood or early adolescence, followed by stability or subtle decreases in late adolescence and adulthood (Amlien et al., 2016; Ducharme et al., 2015; Tamnes et al., 2017; Walhovd et al., 2016b; Wierenga et al., 2014). In terms of spatiotemporal patterns, surface area demonstrates a sensory-to-association gradient of maturation (Amlien et al., 2016; Cafiero et al., 2019; Li et al., 2013).

Studies consistently document larger total surface area in males as compared with females (Amlien et al., 2016; Vijayakumar et al., 2016; Walhovd et al., 2016b; Wierenga et al., 2014). Already shortly after birth, boys have $3.9 \%$ larger surfaces (Jha et al., 2019), and they also show greater expansion of the cortical surface during the first two years of life (Li et al., 2013; Lyall et al., 2015). There is less consensus as to whether males and females have different developmental trajectories after year 2 . A study by Raznahan and colleagues (2011) concluded that females reach maximal surface area earlier than males, while Mills et al. (2014) found this pattern only for certain regions. In contrast, Vijayakumar et al. (2016) found less increases in surface area in females in a few small regions. Several other studies have not observed any sex differences in surface area development (Amlien et al., 2016; Walhovd et al., 2016b; Wierenga et al., 2014).

To conclude, cortical surface area increases rapidly in infancy and continues expansion until late childhood or early adolescence, and while males on average have larger surface area than females, sex differences in development beyond early childhood is not supported.

\subsubsection{Neurobiological processes underlying surface area development}

The surface area of the human cortex is determined by the number of ontogenetic units (Rakic, 1988). Additionally, amplification of several types of radial glia cells likely plays a critical role (Borrell and Götz, 2014). As neurogenesis and neural migration is largely completed shortly after birth, MRI-observed postnatal surface area expansion is probably dominantly driven by local cellular events, including intracortical myelination, gliogenesis, synaptogenesis and dendritic arborization (Hill et al., 2010). Additionally, the width of cortical columns in newborns is about one third of that in adults (Buxhoeveden and Casanova, 2002), and infant areal expansion may thus be explained by increases in columnar width (Lyall et al., 2015).

The cellular processes underlying the more subtle surface area changes observed later in development are less well understood. Seldon (2005) suggested a model where increasing levels of pericortical myelin and axon caliber exert pressure on the cortical surface, causing it to stretch outward, like inflating a balloon. This in turn results in larger cortical surface area, and by extension less cortical folding and thickness. A study by Cafiero and colleagues (2019) demonstrated significant relations between cortical surface area expansion and subcortical myelinated white matter as indexed by $\mathrm{T} 1$ relaxation times. The authors speculated that areal expansion is needed to accommodate increasing amounts of axonal myelin, in line with Seldon's model (Seldon, 2005). However, this theory does not concord with observations indicating continued myelination into adulthood (Grydeland et al., 2019) and subtle reductions in surface area past early adolescence (Amlien et al., 2016; Ducharme et al., 2015; Mills et al., 2014; Raznahan et al., 2011b; Walhovd et al., 2016b; Wierenga et al., 2014).

\subsection{Gyrification}

One of the most apparent characteristics of the human cerebral cortex is its folded structure, a feature that both phylogenetically and ontogenetically in part is related to increasing brain size (Toro et al., 2008), and that mainly develops during the third trimester of fetal life (Armstrong et al., 1995). The spatial positions of sulcal pits, the local 
deepest points of primary sulci that are believed to be the first folds that appear during early brain development, have been found to be temporarily invariant across the second half of gestation and to be similar in the fetal brain in this period and in the adult brain (Yun et al., 2020).

Compared with the morphological features discussed above, developmental changes in the degree of folding across childhood and adolescence have been relatively less explored. Folding, or gyrification, can be quantified at different levels. An early approach was to calculate the ratio between the total cortical surface area relative to the "exposed" surface, also called the hull area (Elias and Schwartz, 1969; Zilles et al., 1988). This was first done globally for the whole cortex, but can also be done for lobes or regions. Building on this approach, Schaer et al. (2012, 2008) developed a method to calculate the local gyrification index, measuring the degree of folding at each specific point of the cortical surface, with higher values reflecting more folding. Other tools are also available for further quantification of aspects of sulcal morphology, including sulcal width, depth and length (Aleman-Gomez et al., 2013; Madan, 2019).

A longitudinal study of 73 infants and toddlers, followed over three time-points in the first two years of life, found that the degree of folding in the cerebral cortex, measured with the gyrification index, increased $16.1 \%$ in the first year and $6.6 \%$ in the second year (Li et al., 2014). The greatest increases were seen in lateral fronto-parietal-temporal cortices, precuneus, and posterior cingulate cortex. Studies capturing these early increases in folding and later developmental changes in the same individuals are lacking, but it is likely that the early increases are followed by decreases in gyrification from around age 4 years (Chen et al., 2012).

From middle childhood, during adolescence, and into young adulthood, longitudinal decreases in the gyrification index have been found at both the global and lobar level. At a global level, this was shown by Raznahan et al. (2011) using the large longitudinal Child Psychiatry Branch NIMH study with $>1250$ longitudinally acquired scans from 647 individuals aged 3-30 years. At the lobe level, a longitudinal study of 52 adolescents scanned twice found that the largest decrease in gyrification was in the frontal lobe (Aleman-Gomez et al., 2013). While significant sulcal widening was found in all lobes, this co-occurred with decreases in sulcal depth in the frontal and occipital lobes only. Partly inconsistent with this spatial pattern, Mutlu et al. (2013) analyzed 209 scans from 137 individuals between the age of 6-30 years and observed linear decreases in local gyrification index across the majority of the cortical surface, but no change in medial and inferior prefrontal, occipital and some lateral temporal cortices. Cross-sectional studies indirectly support the conclusion that cortical folding decreases across adolescence and with a somewhat slower pace in adult age, but also here, different spatial patterns are reported (Cao et al., 2017; Chung et al., 2017; Klein et al., 2014).

Effects of both sex and sex chromosome dosage on gyrification have been shown. The effects are largely consistent with normative scaling laws, with larger brains having disproportionately higher gyrification index due to a relative expansion of total versus hull area (Fish et al., 2016). There are also findings linking age-related decreases in local gyrification to cognitive development (Chung et al., 2017), but longitudinal studies on this are lacking.

To conclude, the degree of folding of the cerebral cortex increases in early childhood, but then decreases from onwards into young adulthood, and while main effects of sex have been found, these appear to be largely explained by normative scaling.

\subsubsection{Neurobiological processes underlying gyrification development}

The neurobiological and biomechanical processes underlying changes in MRI-based gyrification and sulcal morphology during childhood and adolescence are still unclear. Several theories on the folding of the cerebral cortex have been proposed, including explanations based on mechanical tension generated in axons that pull strongly interconnected regions together (Van Essen, 1997), or differential intracortical growth, where certain segments undergo more growth and resulting in local bulges becoming gyri (Caviness, 1975), with some experimental animal studies and mathematical models being consistent with the latter (Bayly et al., 2013; Xu et al., 2010). There remains considerable controversy, however, over the phylogenetic and ontogenetic mechanisms that drive cortical folding (Lewitus et al., 2016; Mota and Herculano-Houzel, 2015; Zilles et al., 2013). Moreover, as highlighted by Cao et al. (2017), most of these theories focus on early brain development, while studies exploring the neurobiological processes explaining gyrification decreases later in childhood and during adolescence are scarce. The suggested possibilities overlap with explanations for developmental changes in surface area, either building on the balloon hypothesis discussed above (Seldon, 2007, 2005) or that dendritic arborization causes release of axonal tension which in turn results in decreasing gyrification (White et al., 2010). Both possibilities currently remain speculations.

\subsection{The developmental relationships between brain morphology measures}

Developmental changes in brain morphology in local regions do not happen in isolation, but rather in coordinated ways within structural networks (Alexander-Bloch et al., 2013; Khundrakpam et al., 2019). Such maturational coupling has been found to be stronger within association areas compared with primary sensory areas (Lerch et al., 2006; Raznahan et al., 2011a), to partly recapitulate known functional networks (Walhovd et al., 2015), and to be associated with cognition (Khundrakpam et al., 2017).

Beyond unimodal morphological assessments, a few studies have also explored the relations between different MRI macrostructural measures from childhood to young adulthood. Understanding these relationships and how they change during development may inform theories about the underlying neurobiology. Cortical volume is conceptually the product of thickness and surface area (Panizzon et al., 2009), while cortical folding has been described as the product of surface area and the square root of cortical thickness (Mota and Herculano-Houzel, 2015). Still, the relations between these brain morphology measures are dynamic across development. Lyall and colleagues (2015) examined relations between cortical thickness and surface area to overall cortical volume in the first two years of life. While they found very weak or no relations between cortical thickness and volume, strong relations were found between surface area and cortical volume in this age group. Furthermore, surface area expansion and cortical thickness growth did not appear to be strongly related. Later in childhood and adolescence, using four independent samples, Tamnes et al. (2017) demonstrated strong positive relations between cortical thinning and cortical volume decreases at the global, lobar, as well as at the vertex-wise level. Positive associations were found also for surface area and volume decreases, however; these relations were weaker. The associations between surface area decreases and cortical thinning were more topologically complex, and less consistent across samples. In general, negative relations were more widespread and identified mainly in gyral and insular regions, while positive relations were less prevalent and primarily located in sulcal regions.

To conclude, relatively few studies have assessed relations between common measures of cortical macrostructure and geometry, but existing studies suggest that the strength and direction of these relations may change as a function of age.

\section{Microstructural development of the cerebral cortex}

Brain microstructure refers to the small tissue subcomponents that together make up the gross shapes, or morphology (macrostructure), of the brain. In the following, microstructural cortical development from young childhood to young adulthood will be primarily assessed through an in-depth review of MRI signal intensity studies. Additionally, cortical MWF and MT will be covered. These methods are more specialized and sensitive to rapid $\mathrm{T} 2$ signal decay, which conventional neuroimaging 
cannot detect (Alonso-Ortiz et al., 2015). Sex differences and biological processes underlying the microstructural changes will also be discussed.

\subsection{Signal intensities}

As detected from MRI, a prominent feature of brain development from childhood to young adulthood is an increase in its brightness. This increase is presumably due to changes in underlying tissue properties (Glasser and Van Essen, 2011). Measures of signal intensity are quantifications of precisely such variations, within and across brain matter. Morphometric measures are certainly also affected, albeit secondarily, by changes in intensity, as strong shifts are used to model the grey/white boundary and to classify voxels as belonging to one tissue class (e.g., grey matter) or another (e.g., cerebrospinal fluid or white matter).

Cortical grey matter intensities are calculated by sampling values across the full-, different fixed-, or percentage depths of the cortical mantle (Glasser and Van Essen, 2011; Salat et al., 2009). White matter intensities are calculated by sampling values extending a shorter millimeter distance into subjacent white matter (Jørgensen et al., 2016; Salat et al., 2009). Grey and white matter intensities can be investigated separately, but this is often challenging in practice as there are inherent intensity differences between individuals, due to individual optimization procedures during scanning (Westlye et al., 2010). Intensities must therefore be normalized, and although there is no convention, common procedures include using intensity values from the ventricles, eyeballs, white matter regions of interest (ROIs), global intensity across the entire head/brain, or outside of the skull. Nevertheless, these approaches have caveats, as normalization values themselves can be associated with other variables, such as age (Norbom et al., 2019), clinical status or head size.

Another approach is to compute a joint T1w grey and white matter intensity measure (Jørgensen et al., 2016; Salat et al., 2009). Grey and white matter can be combined using several slightly different formulas, and in the following they will all be covered by the term "T1w tissue contrasts". It is also possible to compute a purely cortical measure using both the $\mathrm{T} 1 \mathrm{w}$ and $\mathrm{T} 2 \mathrm{w}$ modality, resulting in a T1w/T2w ratio (Glasser and Van Essen, 2011). Usually, a higher T1w tissue contrast indicates greater discrepancies between grey and white matter and vice versa. $\mathrm{T} 1 \mathrm{w} / \mathrm{T} 2 \mathrm{w}$ ratio values above 0 indicate that $\mathrm{T} 2 \mathrm{w}$ intensities are higher than that of $\mathrm{T} 1 \mathrm{w}$ intensities. Consequently, there is an inverse relationship between $\mathrm{T} 1 \mathrm{w}$ tissue contrasts and the $\mathrm{T} 1 \mathrm{w} / \mathrm{T} 2 \mathrm{w}$ ratio.

A few early studies of $\mathrm{T} 1$ relaxation and $\mathrm{T} 1 \mathrm{w}$ intensities within the adult lifespan, reported a progressive decrease in white- to grey matter contrast with increasing age, in specific white-, cortical- and subcortical grey matter regions (Magnaldi et al., 1993; Raz et al., 1990). Keeping several study-caveats in mind, this was the first documentation of intensity sequences being sensitive to fundamental age-related changes in brain tissue. Salat and colleagues (2009) extended this work, also in an adult sample, by performing vertex-wise analyses across the cortex and closely subjacent white matter, and found that age-related alterations in "grey/white ratio" occur in large portions of the cortical mantle.

\subsection{T1w tissue contrasts and $T 1 w / T 2 w$ ratio}

There is presently only a single $\mathrm{T} 1 \mathrm{w}$ tissue contrast study and no $\mathrm{T} 1 \mathrm{w} / \mathrm{T} 2 \mathrm{w}$ ratio studies in youths employing longitudinal designs. Current knowledge about developmental changes in these measures has therefore mainly been indirectly inferred from cross sectional studies, of which highly powered ones are limited. One such T1w grey/white contrast (GWC) study of 1467 participants aged 8-23 years, reported a marked linear age-related decline in global GWC from late childhood to young adulthood (Norbom et al., 2019) (see also (Schwartz et al., 2014)). Occipital, pre- and postcentral cortical regions, parsed through independent component analysis, showed additional negative age effects, while the remaining regions showed either slight or marked linear positive associations with age, results that must be interpreted in addition to the dominant global negative effect (Norbom et al., 2019). Individual differences in regional GWC were also associated with general cognitive ability in a bi-directional cortical pattern. Another GWC study had a partly overlapping sample, but also included younger children, including in a total of 2596 youths aged 3-23 years (Norbom et al., 2020b). This study corroborated age-related results of global GWC showing a steady linear decline with some regional variation, now from early childhood and until young adulthood. Consistent with the findings from Norbom et al. (2019), a separate study that was successfully able to predict age in youths using white/grey contrast, reported that residuals from their age-prediction were highly related to general cognitive ability (Lewis et al., 2018), further suggesting that T1w tissue contrasts are sensitive to aspects of neurocognitive development. However, it is not clear how the developmental patterns reported in these studies relate to grey and white matter intensities separately. A recent study assessed, for the first time longitudinally, GWC in 394 typically developing youths aged 4-22 years, with 1-3 repeated scans per participant resulting in a total of 819 scans (Drakulich et al., 2021). A best-fit vertex-wise model was employed across the cortex, and it was found that GWC nearly globally decreased with increasing age in a cubic (63\%), quadratic (20 $\%)$ or linear (16\%) fashion. Moreover, across development, males showed a limited and region-specific pattern of slightly higher GWC as compared with females.

A lifespan study of the purely cortical measure $\mathrm{T} 1 \mathrm{w} / \mathrm{T} 2 \mathrm{w}$ ratio, which included a subsample of 85 youths aged 8-19 years, found a positive linear association between $\mathrm{T} 1 \mathrm{w} / \mathrm{T} 2 \mathrm{w}$ ratio and age within this age-range (Grydeland et al., 2013). The effect was seen across large portions of the cortex, but was strongest in posterior frontal, parietal, and temporal cortices. Moreover, in the youth group, greater cognitive performance stability was associated with lower T1w/T2w ratio in occipital and parietal regions. Another overlapping lifespan study, which included a subsample of about 200 youths aged 8-23 years, reported that $\mathrm{T} 1 \mathrm{w} / \mathrm{T} 2 \mathrm{w}$ ratio showed early prepubertal growth waves in primary sensory and motor cortices, and later post-pubertal growth waves in association, insular, and limbic cortices (Grydeland et al., 2019). A study of 1555 young adults aged 18-35 years, reported that higher age also in young adulthood was linearly associated with higher T1w/T2w ratio in widespread cortical regions (Shafee et al., 2015). A more recent study of $\mathrm{T} 1 \mathrm{w} / \mathrm{T} 2 \mathrm{w}$ ratio, including young children, with a sample size of 621 youths aged 3-21 years, reported a near global age-related increase in $\mathrm{T} 1 \mathrm{w} / \mathrm{T} 2 \mathrm{w}$ ratio across the cortical surface (Norbom et al., 2020a) (see Fig. 2). There was regional variation, and a general increasing gradient in the strength of the age association from inferior-posterior- to superior-anterior regions. Also, a negative association between $\mathrm{T} 1 \mathrm{w} / \mathrm{T} 2 \mathrm{w}$ ratio and general and several specific cognitive abilities was found, mainly within anterior cortical regions.

Studies testing for possible sex differences in T1w tissue contrasts and $\mathrm{T} 1 \mathrm{w} / \mathrm{T} 2 \mathrm{w}$ ratio in youth development generally report limited main effects (e.g. differences between girls and boys) and interaction effects (e.g. differential associations with age between girls and boys). Norbom et al. (2020b) found limited positive associations between sex and vertex-wise GWC, with boys having higher GWC than girls in occipital and insular subregions. In regards to $\mathrm{T} 1 \mathrm{w} / \mathrm{T} 2 \mathrm{w}$ ratio, Norbom et al. (2020a) found no significant main effects of sex, but a small positive age by sex interaction, indicating that boys in late adolescence had relatively higher $\mathrm{T} 1 \mathrm{w} / \mathrm{T} 2 \mathrm{w}$ ratio than girls in the frontal lobe and parts of the parietal lobe.

To summarize, cortical T1w tissue contrasts and $\mathrm{T} 1 \mathrm{w} / \mathrm{T} 2 \mathrm{w}$ ratio appear to globally and steadily decrease and increase, respectively, from 3 years of age and until young adulthood. These cross-sectional findings indirectly indicate that as the brain matures, grey and white matter intensities become more similar, and the cortex appears brighter in $\mathrm{T} 1 \mathrm{w}$ MRI derived images. Generally, early sensorimotor regions show the most rapid development in childhood, while association and limbic regions, as well as the temporal pole, show a more protracted development. The only longitudinal study of GWC generally concords with-, yet 

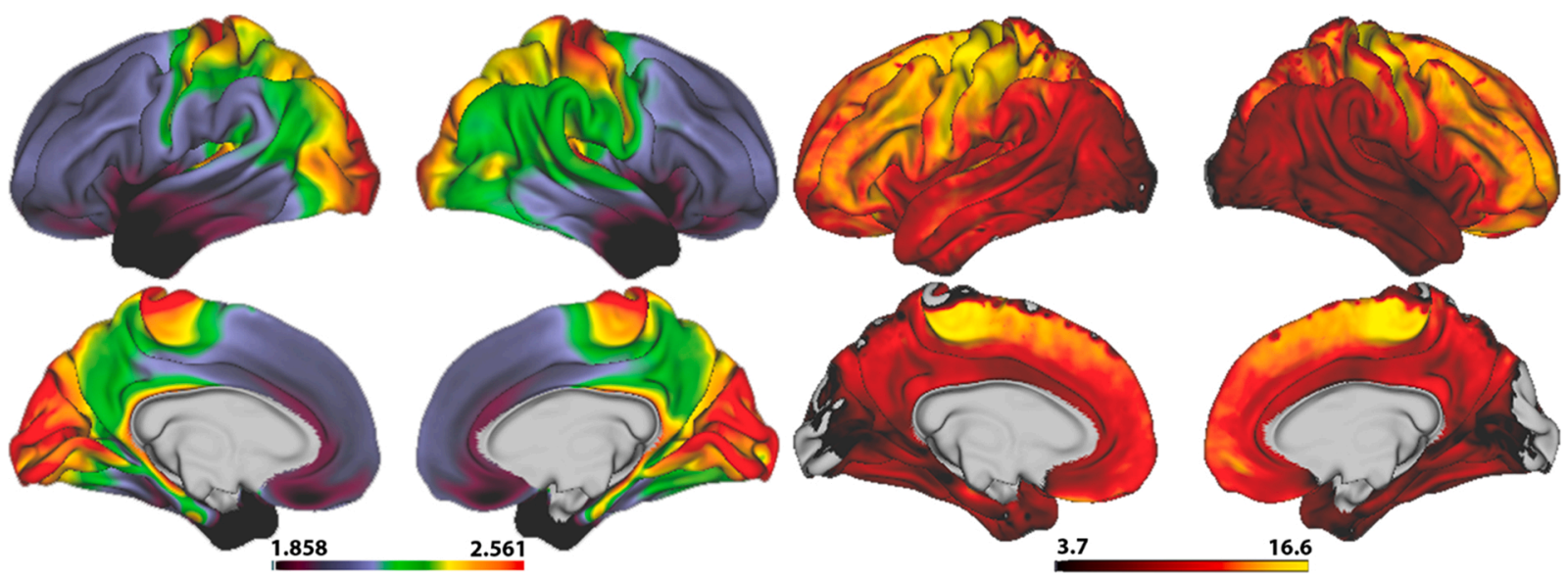

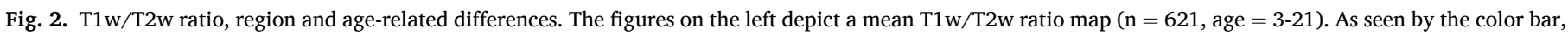

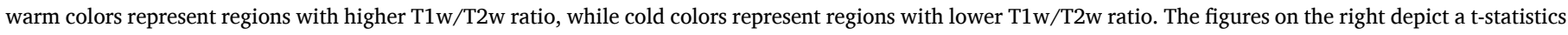

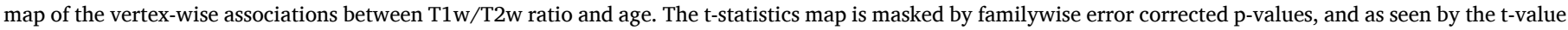
color bar, warm colors represent a positive age association. The figure is adapted from Norbom et al. (2020a).

also modifies our understanding of GWC development, reporting that more than half of the brain shows a cubic developmental pattern. Sex related differences in intensity measures are generally sparse and somewhat conflicting, with reports of higher posterior GWC for boys as compared to girls, and higher frontal $\mathrm{T} 1 \mathrm{w} / \mathrm{T} 2 \mathrm{w}$ ratio in late adolescent boys. Moreover, the few available studies that have examined associations between intensity measures and cognition indicate that these metrics are relevant for individual differences in both general and specific cognitive abilities in youth. GWC shows a bi-directional relationship with general cognitive functioning, while regionally lower T1w/ T2w ratio, especially in frontal regions, has been associated with higher general- and specific cognitive abilities. The direction of these associations could indicate separate neurobiological underpinnings for cognitive and age-related findings, or be explained by an underestimation of the true cortical thickness (see (Norbom et al., 2020a) for in detailed discussion).

\subsubsection{Neurobiological processes underlying T1w tissue contrasts and T1w/ T2 $w$ ratio development}

$\mathrm{T} 1 \mathrm{w}$ tissue contrasts and $\mathrm{T} 1 \mathrm{w} / \mathrm{T} 2 \mathrm{w}$ ratio have both been presumed to indirectly reflect differences in intracortical (and subjacent white matter) myelin content (Glasser and Van Essen, 2011; Salat et al., 2009). Of note, while neuronal axons have diameters in the $\mu \mathrm{m}$ range, cortical microstructure is inferred from large tissue volumes, typically at about 1 $\mathrm{mm}$ voxel resolution (Lazari and Lipp, 2021). Such inferences are possible as macromolecules in the myelin sheath, including cholesterol, have a major influence on T1 longitudinal- and T2 and T2* transverse relaxation times (Does, 2018; Koenig, 1991; Koenig et al., 1990). Other signal influences include iron (Miot-Noirault et al., 1997; Stüber et al., 2014) and water concentration (Miot-Noirault et al., 1997). Human histological studies have reported that $\mathrm{T} 1$ intensity profiles are highly similar to myeloarchitecture (Eickhoff et al., 2005) and that grey matter intensities in the motor/-somatosensory cortical regions are much more impacted by myelin as compared with iron (Stüber et al., 2014). Moreover, it has been reported that $\mathrm{T} 1 \mathrm{w} / \mathrm{T} 2 \mathrm{w}$ values significantly differ between myelinated and demyelinated cortex (Nakamura et al., 2017), and that $\mathrm{T} 1 \mathrm{w} / \mathrm{T} 2 \mathrm{w}$ ratio changes are driven by increased levels of myelin within deeper cortical layers (Shafee et al., 2015).

On the other hand, while there has been no assessments of T1w tissue contrasts, recent attempts have not revealed consistent links between $\mathrm{T} 1 \mathrm{w} / \mathrm{T} 2 \mathrm{w}$ ratio and either myelin-related genes or other suggested MRIbased myelin proxies. For instance, studies have reported low and moderate correlations between $\mathrm{T} 1 \mathrm{w} / \mathrm{T} 2 \mathrm{w}$ ratio and MT in white $(\mathrm{r}=$ 0.38 ) and grey matter $(r=0.54)$, respectively (Hagiwara et al., 2018), and that $\mathrm{T} 1 \mathrm{w} / \mathrm{T} 2 \mathrm{w}$ ratio only shows $11 \%$ shared variance with MWF in all tested grey and white matter regions (Uddin et al., 2019). Similarly, while a study reported low to moderate correlations between $\mathrm{T} 1 \mathrm{w} / \mathrm{T} 2 \mathrm{w}$ ratio and MWF in white matter ROIs, stronger relations were observed for $\mathrm{T} 1 \mathrm{w} / \mathrm{T} 2 \mathrm{w}$ ratio and the intermediate $\mathrm{T} 2$ relaxation time constant, presumed to reflect instead intra and extracellular water mobility (Arshad et al., 2017). Of note, while a study of early white matter development found only weak relations between $\mathrm{T} 1$ relaxation time and MWF (Deoni et al., 2012), the same research group reported a strong relationship within the cerebral cortex, stating that while $\mathrm{T} 1$ is generally non-specific in nature, it may be an acceptable surrogate marker of cortical myelin content during early childhood (Deoni et al., 2015). A combined post-mortem and neuroimaging study reported that other molecular properties such as certain non-myelinating oligodendrocytes, molecular size, axon caliber, and even $\mathrm{pH}$ were more strongly associated with $\mathrm{T} 1 \mathrm{w} / \mathrm{T} 2 \mathrm{w}$ ratio than myelin associated genes, and unexpectedly that the measure was not a proxy for iron content (Ritchie et al., 2018a). Similarly, another study found strong correlations between T1w/T2w ratio and dendrite density rather than myelin content (Righart et al., 2017).

Together, these findings demonstrate that intensity measures are by no means straightforward myelin proxies, and that histological validation studies are needed. Ideally by joint human post-mortem and MRI studies, where the tissue is processed both histologically as well as with neuroimaging, and where variance assessments control for confounders such as axon density and iron content (Lazari and Lipp, 2021). Other complicating factors, such as whether intensity measures capture the same underlying properties across the life-span and within and across brain matter, also need clarification. Moreover, novel neuroimaging methods are continuously developed in an attempt to increase microbiological specificity.

\subsection{Myelin water fraction and magnetization transfer}

One of the more established proposed neuroimaging markers for myelin content is MWF (Laule et al., 2008; Mackay et al., 1994). It is predominantly a white matter measure, with few studies assessing cortical MWF, let alone within typical development (but see (Patel et al., 2019)). MWF is based on the notion that water trapped between lipid layers of the myelin sheath have shorter $\mathrm{T} 2$ relaxation time, while intraand extra axonal water have much longer relaxation. MWF, based on the $\mathrm{T} 2$ sequence is the ratio of myelin water (the short T2 signal) relative to the total water content (the total T2 signal) (Alonso-Ortiz et al., 2015).

A cross-sectional cortical MWF study of 215 children aged 1-6 years 
reported that already at one year of age, high MWF was found in somatosensory, motor, visual, auditory and superior temporal cortices (Deoni et al., 2015). In contrast, the temporal pole, prefrontal and association cortex showed relatively low MWF, but also a more protracted development, broadly mirroring established histological timelines of intracortical myelin. The study found no hemispheric or sex related differences (Deoni et al., 2015).

MT is another established proposed neuroimaging myelin marker, which also has been predominantly assessed in white matter. The measure, based on the T2 sequence, is based on hydrogen protons being present in three different forms within the brain, namely as "free water", in "macromolecules" and between the two as "bound water" in hydration layers (Sled, 2018). While free water is unstructured with rapidly rotating molecules, protons in macromolecules and (to a lesser extent) bound water have highly restricted motion (Pike, 1996; Stanisz et al., 1999). To assess MT a targeted radio frequency (RF) pulse saturates the protons in macromolecules, which then partially transfer their magnetization onto protons in the other two sites. Another RF pulse now targeting free water protons is employed, resulting in a reduced signal due to the previous transfer of magnetization (Boer, 1995; Sled, 2018). The signal difference between these RF pulses is referred to as the magnetization transfer ratio (MTR). The cortical MT signal has also been associated with dendritic arbour (Patel et al., 2019).

A recent cross-sectional study of cortical MT in 297 youths aged 14-24 years found that association areas had lower MT as compared with primary cortical areas at age 14, but that association areas had faster rates of MT increases throughout adolescence (Whitaker et al., 2016). Moreover, at age 14 MT was highest in deeper cortical layers, possibly reflecting a greater density of myelinated fibers. Another study of 150 adolescents confirmed the age-related increase in average MT using longitudinal data (Patel et al., 2019). These findings were recently corroborated by an accelerated longitudinal study using an overlapping sample as employed by Whitaker et al. (2016) of 234 youths aged 14-27 years, which reported an overall developmental increase in mean MT, as well as independent increases in mid to deep cortical layers (Paquola et al., 2019). Both effects were particularly strong in uni- and heteromodal association cortices. Another accelerated longitudinal study, again with an overlapping sample of 288 youths, reported that early life economic disadvantage was associated with lower rates of MT in multiple cortical regions, including in mid- and posterior cingulate, precuneus, insular and prefrontal cortices (Ziegler et al., 2020). At present, few studies have explored MWF and MT in the cerebral cortex, yet both measures potentially give valuable information for assessing cortical microstructural properties, and may increase the neurobiological specificity of MRI studies of brain development. In one study that assessed both measures simultaneously, no relationship between the two measures was observed when correlated across the cerebral cortex, thus pointing to different neurobiological sources of MTR and MWF in cortical gray-matter (Patel et al., 2020).

\section{Integrating macro- and microstructural development of the cerebral cortex}

A few studies have attempted, through vertex-wise correlational and multimodal fusion methods, to explore the relationship between brain morphology and microstructure in children and adolescents. Indirectly these studies aim to improve the neurobiological specificity of agerelated findings, as for instance illustrated by a cross-sectional lifespan study which was able to differentiate MRI-based cortical thinning in youth development from thinning in senescence through its inverse relationship with cortical grey matter intensities (Westlye et al., 2010).

A large cross-sectional study focusing on young adulthood found that the $\mathrm{T} 1 \mathrm{w} / \mathrm{T} 2 \mathrm{w}$ ratio was negatively correlated with global cortical thickness $(r=-0.32)$, but that the regional associations varied in direction (Shafee et al., 2015). Another recent study employing multimodal fusion to investigate the relationships between cortical thickness, surface area and GWC in children and adolescents found several components that captured largely corresponding regions across modalities (Norbom et al., 2020b). In these instances, in accordance with the findings of Shafee and colleagues (2015), GWC and thickness generally showed directional weighting correspondence (i.e. higher thickness and GWC), which was opposite to that of surface area (i.e. smaller surface area). There was, however, an important exception to this finding, as one of the components reflecting global cortical thickness and GWC with opposite weighting showed a negative age association, indicating that the cortex becomes thinner and darker with increasing age. This could be additional evidence for the notion that as the intensity in deep cortical layers rises, these voxels are misclassified by imaging software as white matter, resulting in an outward shifting of the grey/white border and consequently an underestimation of the true cortical thickness and brightness (Norbom et al., 2020b). All findings considered, the cortex appears to become thinner and brighter from childhood to young adulthood, findings that in actuality might be over- and underestimated respectively.

Apart from intensity metrics, a cross-sectional study of adolescents and young adults found a strong negative association between cortical thickness and MT (Whitaker et al., 2016). This study also found that age-related thickness differences were significantly, but not entirely mediated by differences in MT, indicating that myelination is not the sole reason for developmental cortical thinning. Another study assessed multiple macro- and microstructural neuroimaging measures, including mean diffusivity, quantitative $\mathrm{T} 1$, and cortical thickness, within a region of the visual cortex in 27 children aged 5-9 years and 30 adults aged 22-28 years (Natu et al., 2019). Age-group differences were reported for quantitative T1 and MD in mid and deep cortical layers, both with a negative association. Further, these differences were related to cortical thickness, or more specifically to an increasing underestimation of cortical thickness. The study concluded, based on the multimodal pattern of results, albeit from a single cortical region, that the cortex does not thin during childhood but instead becomes more myelinated (Natu et al., 2019). Thus, recent multimodal studies consistently report that apparent cortical thinning in youth development is overestimated. If this is in part, or fully, due to pericortical myelination and the possible regional variation in these relationships, needs clarification.

\section{Leveraging transcriptomics to probe the cellular neurobiology of cerebral cortical development}

Recently, neuroimaging studies have begun to leverage cortical gene expression to understand the neurobiology underlying cortical structure in the developing brain. These studies build on previous work such as ex vivo histological studies of cortical neurobiology. To do so, inter-regional variations in MRI phenotypes are compared with inter-regional variations in gene expression. By establishing which genes have expression patterns similar to the profile of the imaging phenotype of interest, one can infer biological processes and cellular involvement underlying regional variations in brain structure and structural change. This burgeoning area of research has been facilitated by recent efforts to characterize the brain's transcriptome, that is, the total set of RNA transcripts expressed in the brain. In particular, the Allen Human Brain Atlas (https://portal.brain-map.org/) has contributed the most extensive spatial sampling across regions of the adult brain (Hawrylycz et al., 2015, 2012). With post-mortem MRI scans of six donor brains, and tissue samples additionally having been mapped to MNI coordinate space, this resource substantially aids in the comparison of gene expression with cortical brain phenotypes. Notably, the BrainSpan atlas (https://www. brainspan.org/) provides the most extensive spatial sampling of the developing human brain, from fetal development into adulthood (Kang et al., 2011; Li et al., 2018). These transcriptional resources have been used to study molecular features relevant to brain development, such as the relationship between sex and stress hormone receptor gene expression in association with cortical thinning during adolescence (French 
and Paus, 2015; Parker et al., 2017, 2020b; Shin et al., 2018; Wong et al., 2018) or biological processes that are enriched among genes associated with cortical profiles of MT and areal expansion of the cortex (Reardon et al., 2018; Whitaker et al., 2016). It is important to note that, for these studies, the sources of gene expression (e.g., Allen Human Brain Atlas) differs from the source of brain phenotypes (i.e., study specific imaging).

This section will focus on reviewing studies that investigate the cellular neurobiology of cortical development using gene expression. Single-cell transcriptomic analyses of rodent and human brain tissue has provided several sets of genes specific to neural cell types (Darmanis et al., 2015; Lake et al., 2018; Zeisel et al., 2015; Zhang et al., 2014). Therefore, scientists can test which neural cell types contribute to the spatial variation in brain phenotypes by leveraging spatial gradients in cell-specific gene expression. This is accomplished using various methods that quantify the potential extent of cellular involvement such as over-representation analysis, gene set enrichment analysis, or virtual histology (Boyle et al., 2004; Maere et al., 2005; Shin et al., 2018; Subramanian et al., 2005).

\subsection{Brain transcriptomics and the cellular neurobiology of cortical macrostructure}

Cortical thickness and age-related thinning are the neuroimaging phenotype that have most often been associated with the transcriptional signatures of neural cells. From 4.5 years to 21 years of age, interregional patterns of cortical thickness have consistently been associated with the gradients in neuronal- and astrocyte-specific gene expression across three independent studies (Patel et al., 2020; Pecheva et al., 2020; Shin et al., 2018). The pattern of associations (i.e., greater expression, greater thickness) may suggest that regions with thicker cortex have greater neuronal and astrocyte cell densities. This is supported by histological evidence that more complex neuronal architecture and a larger population of glial cells are associated with thicker cortex (Carlo and Stevens, 2013; Goriounova et al., 2018). Additionally, spatial variations in cortical thickness have also been associated with transcriptional gradients in oligodendrocyte and microglial genes in infants and adolescents, respectively (Pecheva et al., 2020; Shin et al., 2018). Histological studies report that cortical myelin increases from birth through early adulthood, suggesting that oligodendrocytes play a role in shaping cortical morphology (Miller et al., 2012). Additionally, synapse formation early in life is followed by a period of elimination in childhood through early adulthood (Huttenlocher, 1979; Huttenlocher and Dabholkar, 1997; Petanjek et al., 2011). Microglia play a major role at the synapse both in modulation of synaptic transmission and in synapse elimination (Kettenmann et al., 2013). Although cortical tissue is composed of neurons, glia, and vasculature, novel transcriptional evidence indicates that astrocytes and neuronal cells may contribute the most prominently to the spatial variations in cortical thickness in the developing brain.

Several studies have used gene expression to assess age-related changes in cortical thickness. Three independent investigations reported that, during childhood and adolescence, regional variations in cortical thinning were associated with the pattern of gene expression specific to neurons (Ball et al., 2020; Shin et al., 2018; Vidal-Pineiro et al., 2020). In particular, regions with lower pyramidal cell expression had greater cortical thinning (Shin et al., 2018; Vidal-Pineiro et al., 2020) (see Fig. 3). Therefore, this is in concurrence with hypotheses that suggest reductions in dendritic branching may underlie cortical thinning, as derived from post-mortem histology (Huttenlocher, 1979; Huttenlocher and Dabholkar, 1997; Petanjek et al., 2011). With respect to glial cells, cortical regions with lower expression of astrocyte and microglia genes have greater cortical thinning (Shin et al., 2018; Vidal-Pineiro et al., 2020). Since these cells play a supporting role at the synapse, loss of spines may translate into local reductions in the involvement of astrocytes and microglia (Ben Achour and Pascual, 2010; Kettenmann et al., 2013). Consistent with histological studies describing increases in myelination during maturation (Miller et al., 2012), regions of the brain with greater myelin-related gene expression have been associated with greater cortical thinning (Parker et al., 2020a). Moreover, greater oligodendrocyte gene expression in cortical regions with greater age-related decreases in thickness has been reported in male adolescents, but not females (Shin et al., 2018). One could speculate that as the human cortex develops, there might be reduced necessity of astrocyte and microglial support in cortical regions with greater myelination. Ultimately, this cascade of cellular effects, coupled with an outward encroachment of the grey/white boundary, may result in MRI-based cortical thinning during childhood and adolescence.

\subsection{Brain transcriptomics and the cellular neurobiology of cortical microstructure}

A number of studies have investigated the neurobiology of cortical microstructure during development using transcriptomic signatures of neural cell-types. For instance, greater oligodendrocyte gene expression has been associated with shorter T2 relaxation times, longitudinal increases in MT, higher T1w/T2w ratio, and greater MWF (Patel et al., 2020, 2019). Gradients in expression of oligodendrocyte genes and myelin-basic protein have also been linked to cortical variations in measures of MT during development (Paquola et al., 2019; Whitaker et al., 2016). Histological studies have reported that myelin content is associated with several of these imaging derived phenotypes, such as MT and MWF (Laule et al., 2006; Reeves et al., 2016). Histological evidence, however, also suggests that myelin content may not be the only source of signal for these measures of cortical microstructure (Reeves et al., 2016; Righart et al., 2017). Transcriptomic signatures of cell-types other than oligodendrocytes have also been associated with the signal of these neuroimaging phenotypes. A study of 507 males aged 18-21 years discovered that regions of the cerebral cortex with less astrocyte-specific gene expression had greater MWF and $\mathrm{T} 1 \mathrm{w} / \mathrm{T} 2 \mathrm{w}$ ratio. These regions also had shorter $\mathrm{T} 1$ and $\mathrm{T} 2$ relaxation times (Patel et al., 2020). This is an example of how anti-correlated profiles of cortical phenotypes (i.e., MWF and T1w/T2w vs T1 and T2 relaxation times) will be co-localized with similar, but opposite, transcriptional gradients and therefore, may implicate the same cell-types. A study of cortical MTR reported that inter-regional variations were associated with pyramidal and ependymal cell-specific gene expression (Patel et al., 2019). Altogether, this may suggest that variations in neuronal and glial cell densities, the complexity of their cellular protrusions, and their macro- and micromolecular contents may contribute to MRI derived measures of cortical microstructure. Therefore, many of the neuroimaging phenotypes thought to be associated with myelin content may in fact reflect a variety of other neural cells in addition to myelin producing oligodendrocytes.

Overall, studies leveraging transcriptomic signatures of neural cellspecific genes have provided insight into the neurobiology underlying spatial variations in cortical structure. Across development, these macro- and microstructural features share similarities in the cellular underpinnings contributing to their variation. Replication of these novel findings is warranted.

\section{Discussion and conclusion}

We have reviewed modern uni- and multimodal MRI research and reported on the current understanding of macro- and microstructural development of the human cerebral cortex from early childhood, through adolescence, and until young adulthood. Further, we have discussed the possible underlying neurobiological processes of changes in MRI metrics, bridging classic theories from ex-vivo histology to in-vivo findings from current transcriptomics research.

Concerning morphology, cortical volume increases in the first 2 years of life, before generally decreasing, while showing peaks in certain regions before late childhood. Similarly, beyond an initial increase in the first 2 years of life, the cerebral cortex shows a region specific pattern of 


\section{a. Single Cortical Phenotype vs Single Gene}

Study

specific

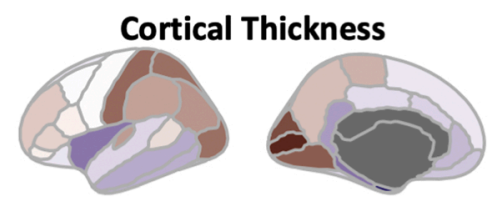

\section{Glucocorticoid Receptor} mRNA Expression

Allen Human Brain Atlas
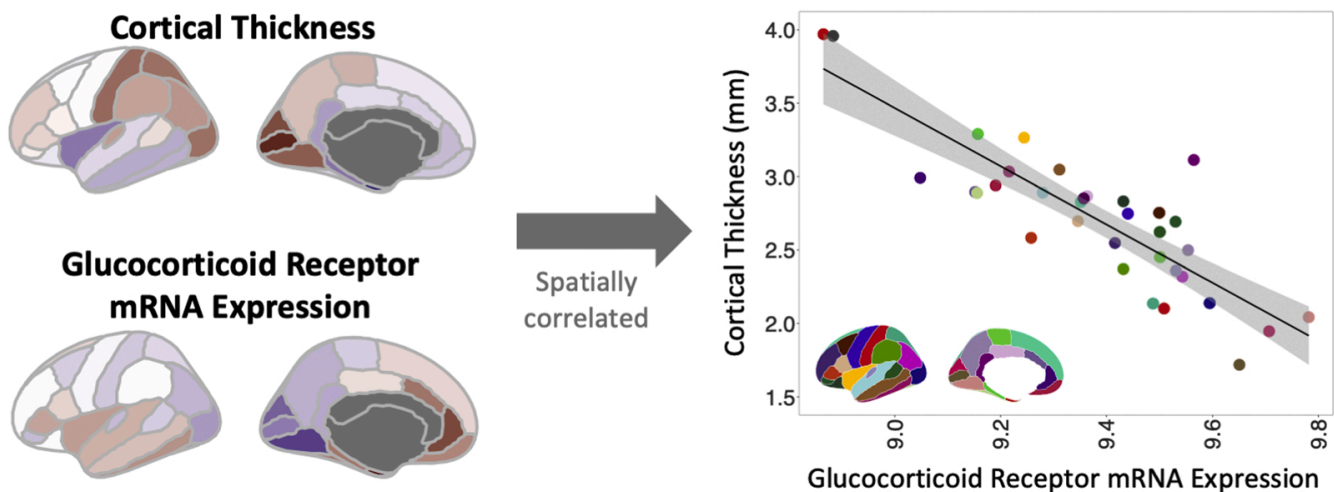

Glucocorticoid Receptor mRNA Expression

\section{b. Single Cortical Phenotype vs Cell-Specific Gene Expression}
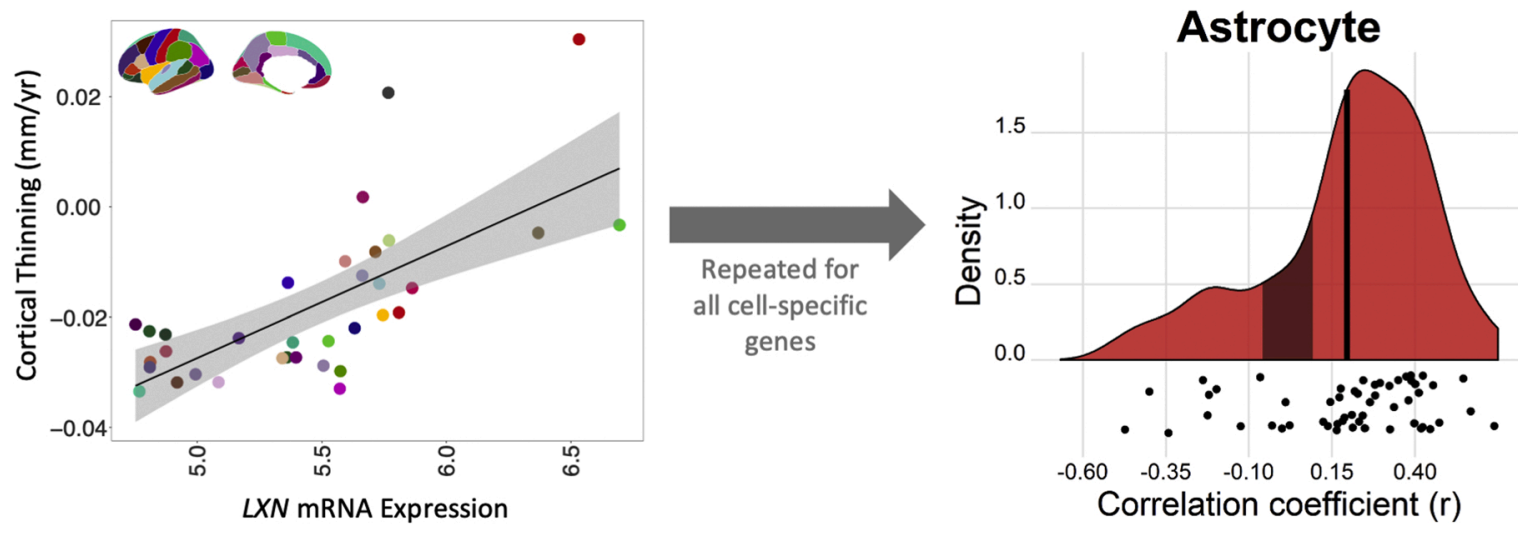

\section{c. Multiple Cortical Phenotypes vs Multiple Cell-Specific Gene Expression Panels}
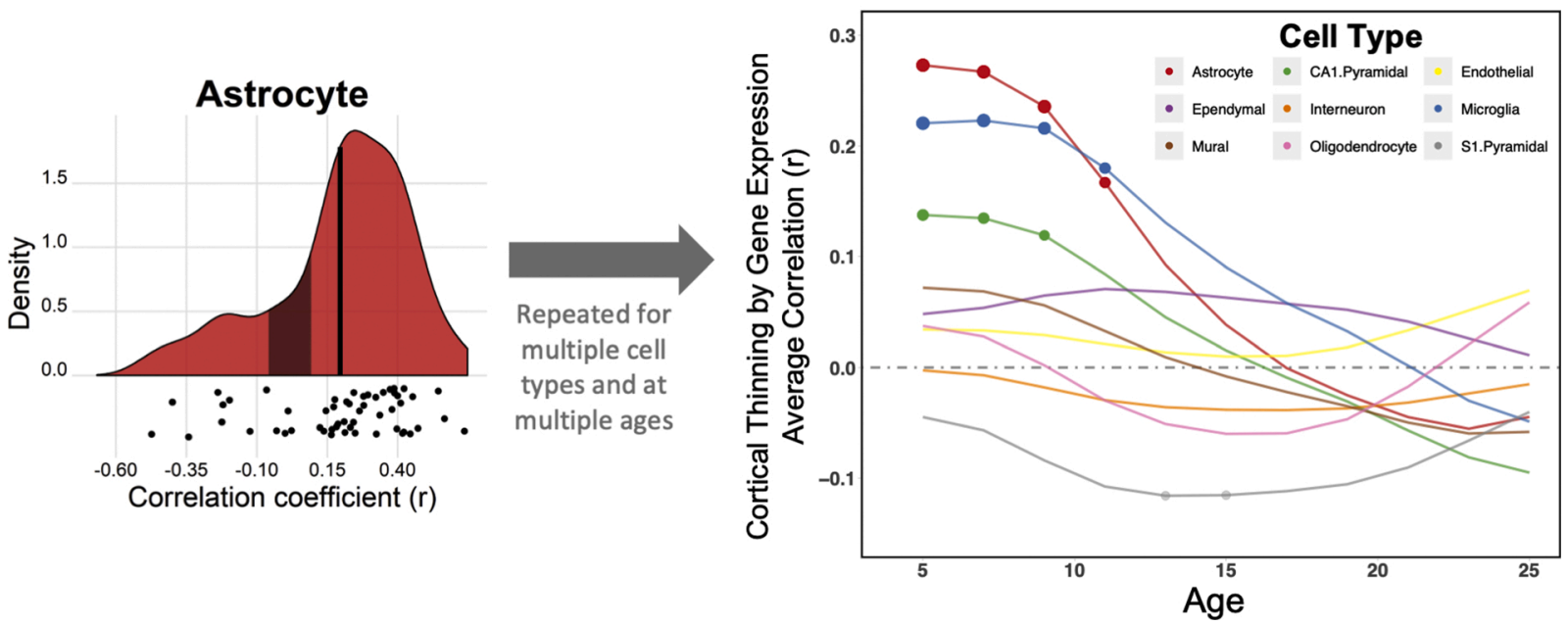

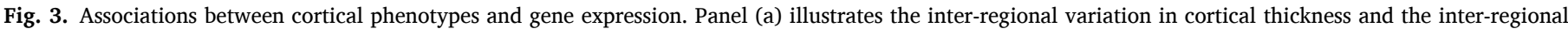

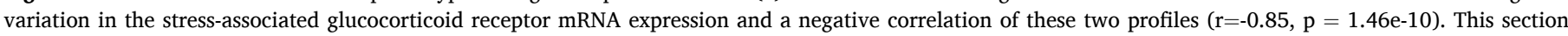

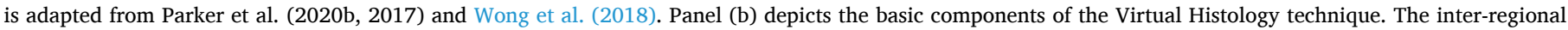

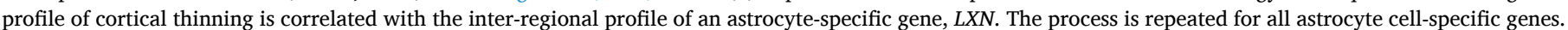

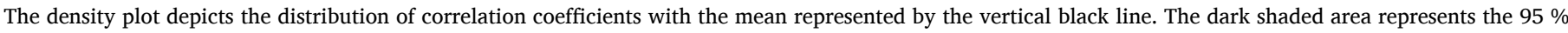

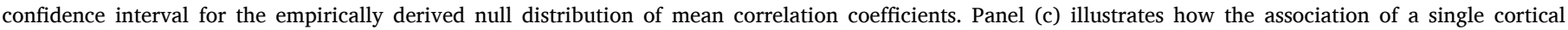

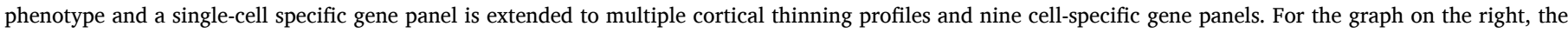

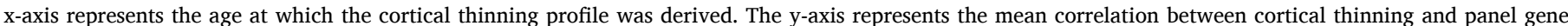

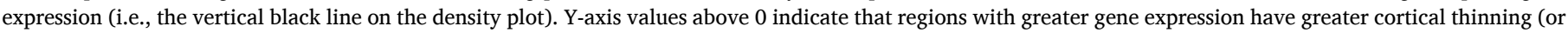

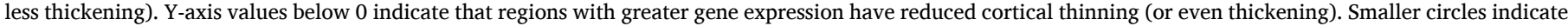
a $\mathrm{p}<0.05$ and larger circles indicate $\mathrm{p}<0.0001$. Sections $\mathrm{b}$ and $\mathrm{c}$ are adapted from Vidal-Pineiro et al. (2020). 
monotonic cortical thinning across development, with possibly a slight acceleration in adolescence. Surface area massively increases the firstand to a lesser extent the second year of life, and in most regions probably continues to expand, reaching peaks in late childhood, followed by subtle decreases across adolescence. Cortical folding initially increases with a regional pattern, before likely decreasing after age 4 years. The complex multimodal relationship between these macrostructural measures appears to change in both strength and even direction as a function of age.

Microstructural changes include global steady decreases in cortical $\mathrm{T} 1 \mathrm{w}$ tissue contrasts and increases in $\mathrm{T} 1 \mathrm{w} / \mathrm{T} 2 \mathrm{w}$ ratio from 3 years of age and until young adulthood, indicating that the cortex becomes brighter, resulting in a blurring of the grey and white matter boundary. Early sensorimotor regions show rapid development in childhood, while higher-order association and limbic regions show protracted development. Concordantly, MWF and MT generally show similar developmental patterns as intensity metrics. In youth development, the complex relationship between macro and microstructural measures point to the cortex becoming thinner, larger in area during childhood and brighter.

While an increasing number of longitudinal studies have charted cortical macrostructural development (Gao et al., 2019; Vijayakumar et al., 2018), there are few developmental- and presently only a single longitudinal study employing MRI signal intensity metrics to probe cortical microstructural development. Strong relations between intensity metrics and age have however been found across childhood, adolescence and young adulthood, possibly even stronger than those seen for morphometric measures (Norbom et al., 2020b). Individual differences in signal intensity metrics in children and adolescents also show associations with cognitive abilities and neurodevelopmental psychopathology, but further studies are needed to understand the spatiotemporal dynamics of these relationships (Grydeland et al., 2013; Lewis et al., 2018; Norbom et al., 2020a, 2019).

It is challenging to link developmental changes in cortical macroand microstructure to specific underlying neurobiological processes, and theories are often based on post-mortem histological- and indirect multimodal and quantitative MRI assessments. Novel transcriptomic studies have recently supplemented such studies. Transcriptomic studies have reported relations between cortical thinning in childhood and adolescence to lower pyramidal cell expression (Shin et al., 2018; Vidal-Pineiro et al., 2020), concurring with post-mortem theories of reduction in dendritic spines (Huttenlocher, 1979; Huttenlocher and Dabholkar, 1997; Petanjek et al., 2011). Also, transcriptomic studies have found associations between cortical thinning and lower expression of astrocyte and microglia genes (Shin et al., 2018; Vidal-Pineiro et al., 2020) of which there might be reduced necessity for in regions with greater myelination. Concordantly, greater myelin-related gene expression has been associated with greater cortical thinning from late childhood to adolescence (Parker et al., 2020a). Of note, these studies are based on group-level regional associations and not on individual differences. Still, transcriptomic studies more broadly implicate the involvement of the cortical cellular environment, and appear to offer a highly fruitful link between ex-vivo post-mortem and in-vivo neuroimaging studies.

It is not unlikely that there would be sex-related differences in cortical structure and development, as there are well-known differences in the age of onset and duration of the pubertal period, as well as separate hormonal influences (Herting and Sowell, 2017; Marshall and Tanner, 1970, 1969; Peper et al., 2011; Peper and Dahl, 2013). Moreover, there are sex-related age of onset and overall risk discrepancies for developing several mental disorders (Häfner et al., 1993; Kessler et al., 2005), and studies have also reported subtle sex-related differences in selected cognitive functions (Jones et al., 2003; Sommer, 2004). It is therefore noteworthy that there appears to be limited sex-differences in cortical macro- and microstructural development. An exception is surface area, where young males have larger area (Amlien et al., 2016; Vijayakumar et al., 2018; Walhovd et al., 2016b; Wierenga et al., 2014), and show greater areal expansion during the first years of life as compared to young females (Li et al., 2013; Lyall et al., 2015). However, recent studies measuring the spread instead of the center, indicate sex differences in inter-individual brain variability, suggesting that future studies should go beyond group-level mean differences (Forde et al., 2020; Ritchie et al., 2018b; Wierenga et al., 2020, 2018). Moreover, creating continuous instead of binary sex scores have also successfully captured inter-individual variability in several brain- and other phenotypes (Vosberg et al., 2020). Also, to capture effects of pubertal and hormonal changes on brain structure and development, studies with relatively more intensive longitudinal designs might be needed (Herting and Sowell, 2017). Nevertheless, female and male brains do not belong to distinct categories (Joel et al., 2015) and brain architecture typical of males are also typical of females, with substantially overlapping distributions (Alon et al., 2020; Vosberg et al., 2020). Rather, individual brains appear to be comprised of unique "mosaics" of features, some more common in each sex (Joel et al., 2015).

Further longitudinal studies are needed to more directly and accurately delineate the developmental trajectories of intensity based cortical microstructure. Future studies should also further investigate the multimodal relationships between cortical macro- and microstructural metrics longitudinally. These are as cross-sectional studies suggest complex and may involve age-variant relationships. Future studies should also integrate imaging modalities and seek to increase our understanding of the spatiotemporal dynamics of the relationships between brain structural and microstructural development and brain functional development, which involves increasing within-network connectivity, decreasing between-network connectivity and changes in neural responses during task performance (Fan et al., 2021; Mills and Tamnes, 2020; Overbye et al., 2018; Sherman et al., 2014).

Possible sex differences in cortical microstructure could be estimated through brain variability, and non-binary sex continuum approaches which have been profitable for assessing differences in cortical morphology. Beyond quantitative T1 and T2 approaches, the biological specificity of microstructural measures using the weighted sequences need stringent testing through both post-mortem and transcriptomics approaches. Further, prenatal and postnatal brain development is often explored separately due to the expertise of the researchers. Future collaborative efforts across these fields should seek to better integrate the study of brain developmental changes in utero and in infancy, childhood and adolescence. Of note, patterns of brain structural development discussed in this paper are largely based on group-level estimates. There is a growing emphasis on individual differences in brain structural development (Becht and Mills, 2020; Foulkes and Blakemore, 2018; Mills et al., 2021), and the importance of this heterogeneity in brain developmental patterns for cognition and behavior (e.g. (Bos et al., 2018; Schnack et al., 2015)). Relatedly, the neuroimaging literature increasingly considers the developing brain in context, probing the dynamic relations between brain structure and function and culture, ethnicity and socio-economic factors (Farah, 2017; Noble and Giebler, 2020; Qu et al., 2021). Growing insight into these complex relations may also shape the methods in pediatric imaging in the years to come (Zhao et al., 2019).

\section{Funding}

This work was supported by the Research Council of Norway (\#223273,\#288083) and theSouth-Eastern Norway Regional Health Authority (\#2019069,\#2021070,\#500189).

\section{Appendix A. The Peer Review Overview and Supplementary data}

The Peer Review Overview and Supplementary data associated with this article can be found in the online version, at doi:https://doi.org/10 .1016/j.pneurobio.2021.102109. 


\section{References}

Akshoomoff, N., Newman, E., Thompson, W.K., McCabe, C., Bloss, C.S., Chang, L., Amaral, D.G., Casey, B.J., Ernst, T.M., Frazier, J.A., Gruen, J.R., Kaufmann, W.E., Kenet, T., Kennedy, D.N., Libiger, O., Mostofsky, S., Murray, S.S., Sowell, E.R., Schork, N., Dale, A.M., Jernigan, T.L., 2014. The NIH Toolbox Cognition Battery: results from a large normative developmental sample (PING). Neuropsychology 28 , 1-10. https://doi.org/10.1037/neu0000001.

Aleman-Gomez, Y., Janssen, J., Schnack, H., Balaban, E., Pina-Camacho, L., AlfaroAlmagro, F., Castro-Fornieles, J., Otero, S., Baeza, I., Moreno, D., Bargallo, N., Parellada, M., Arango, C., Desco, M., 2013. The human cerebral cortex flattens during adolescence. J. Neurosci. 33, 15004-15010. https://doi.org/10.1523/ JNEUROSCI.1459-13.2013.

Alexander-Bloch, A., Giedd, J.N., Bullmore, E., 2013. Imaging structural co-variance between human brain regions. Nat. Rev. Neurosci. 14, 322-336. https://doi.org/ $10.1038 / \mathrm{nrn} 3465$.

Alexander-Bloch, A., Clasen, L., Stockman, M., Ronan, L., Lalonde, F., Giedd, J., Raznahan, A., 2016. Subtle in-scanner motion biases automated measurement of brain anatomy from in vivo MRI: motion Bias in Analyses of Structural MRI. Hum. Brain Mapp. 37, 2385-2397. https://doi.org/10.1002/hbm.23180.

Alnæs, D., Kaufmann, T., Marquand, A.F., Smith, S.M., Westlye, L.T., 2020. Patterns of sociocognitive stratification and perinatal risk in the child brain. Proc. Natl. Acad. Sci. 117, 12419-12427. https://doi.org/10.1073/pnas.2001517117.

Alon, N., Meilijson, I., Joel, D., 2020. Testing the masculinization hypothesis in a sample of 23,935 human brains. bioRxiv. https://doi.org/10.1101/2020.11.09.373258, 2020.11.09.373258

Alonso-Ortiz, E., Levesque, I.R., Pike, G.B., 2015. MRI-based myelin water imaging: a technical review: MRI-Based myelin water imaging. Magn. Reson. Med. 73, 70-81. https://doi.org/10.1002/mrm.25198.

Amlien, I.K., Fjell, A.M., Tamnes, C.K., Grydeland, H., Krogsrud, S.K., Chaplin, T.A., Rosa, M.G.P., Walhovd, K.B., 2016. Organizing principles of human cortical development-thickness and area from 4 to 30 years: insights from comparative primate neuroanatomy. Cereb. Cortex 26, 257-267. https://doi.org/10.1093/ cercor/bhu214.

Andrews, J.L., Ahmed, S.P., Blakemore, S.-J., 2021. Navigating the social environment in adolescence: the role of social brain development. Biol. Psychiatry 89, 109-118. https://doi.org/10.1016/j.biopsych.2020.09.012.

Armstrong, E., Schleicher, A., Omran, H., Curtis, M., Zilles, K., 1995. The ontogeny of human gyrification. Cereb. Cortex 5, 56-63. https://doi.org/10.1093/cercor/5.1.56.

Arshad, M., Stanley, J.A., Raz, N., 2017. Test-retest reliability and concurrent validity of in vivo myelin content indices: myelin water fraction and calibrated $\mathrm{T}_{1} \mathrm{~W} / \mathrm{T}_{2} \mathrm{~W}$ image ratio: test-Retest Reliability and Concurrent Validity of in Vivo Myelin Content Indices. Hum. Brain Mapp. 38, 1780-1790. https://doi.org/10.1002/ hbm. 23481.

Ball, G., Seidlitz, J., Beare, R., Seal, M.L., 2020. Cortical remodelling in childhood is associated with genes enriched for neurodevelopmental disorders. NeuroImage 215 116803. https://doi.org/10.1016/j.neuroimage.2020.116803.

Bastos, A.M., Usrey, W.M., Adams, R.A., Mangun, G.R., Fries, P., Friston, K.J., 2012. Canonical microcircuits for predictive coding. Neuron 76, 695-711. https://doi.org/ 10.1016/j.neuron.2012.10.038.

Batalle, D., Edwards, A.D., O'Muircheartaigh, J., 2018. Annual Research Review: not just a small adult brain: understanding later neurodevelopment through imaging the neonatal brain. J. Child Psychol. Psychiatry 59, 350-371. https://doi.org/10.1111/ jcpp. 12838 .

Bayly, P.V., Okamoto, R.J., Xu, G., Shi, Y., Taber, L.A., 2013. A cortical folding model incorporating stress-dependent growth explains gyral wavelengths and stress patterns in the developing brain. Phys. Biol. 10, 016005 https://doi.org/10.1088/ 1478-3975/10/1/016005.

Becht, A.I., Mills, K.L., 2020. Modeling individual differences in brain development. Biol. Psychiatry 88, 63-69. https://doi.org/10.1016/j.biopsych.2020.01.027.

Ben Achour, S., Pascual, O., 2010. Glia: the many ways to modulate synaptic plasticity. Neurochem. Int. 57, 440-445. https://doi.org/10.1016/j.neuint.2010.02.013.

Blakemore, S.-J., 2012. Imaging brain development: the adolescent brain. NeuroImage 61, 397-406. https://doi.org/10.1016/j.neuroimage.2011.11.080.

Blakemore, S.-J., Mills, K.L., 2014. Is adolescence a sensitive period for sociocultural processing? Annu. Rev. Psychol. 65, 187-207. https://doi.org/10.1146/annurevpsych-010213-115202.

Boer, R.W., 1995. Magnetization transfer contrast Part 1 : MR physics. Philips Medical Systems MedicaMundi 64-73.

Borrell, V., Götz, M., 2014. Role of radial glial cells in cerebral cortex folding. Curr. Opin. Neurobiol. 27, 39-46. https://doi.org/10.1016/j.conb.2014.02.007.

Bos, M.G.N., Peters, S., van de Kamp, F.C., Crone, E.A., Tamnes, C.K., 2018. Emerging depression in adolescence coincides with accelerated frontal cortical thinning. J. Child Psychol. Psychiatry 59, 994-1002. https://doi.org/10.1111/jcpp.12895.

Bourgeois, J., Rakic, P., 1993. Changes of synaptic density in the primary visual cortex of the macaque monkey from fetal to adult stage. J. Neurosci. 13, 2801-2820. https:// doi.org/10.1523/JNEUROSCI.13-07-02801.1993.

Boyle, E.I., Weng, S., Gollub, J., Jin, H., Botstein, D., Cherry, J.M., Sherlock, G., 2004. GO::TermFinder-open source software for accessing Gene Ontology information and finding significantly enriched Gene Ontology terms associated with a list of genes. Bioinformatics 20, 3710-3715. https://doi.org/10.1093/bioinformatics/bth456.

Brodmann, K., 1909. Vergleichende Lokalisationslehre der Grosshirnrinde in ihren Prinzipien dargestellt auf Grund des Zellenbaues. Barth.

Brown, T.T., Jernigan, T.L., 2012. Brain Development During the Preschool Years. Neuropsychol. Rev. 22, 313-333. https://doi.org/10.1007/s11065-012-9214-1.
Buxhoeveden, D.P., Casanova, M.F., 2002. The minicolumn and evolution of the brain. Brain Behav. Evol. 60, 125-151. https://doi.org/10.1159/000065935.

Bystron, I., Blakemore, C., Rakic, P., 2008. Development of the human cerebral cortex: boulder Committee revisited. Nat. Rev. Neurosci. 9, 110-122. https://doi.org/ 10.1038/nrn2252.

Cafiero, R., Brauer, J., Anwander, A., Friederici, A.D., 2019. The concurrence of cortical surface area expansion and white matter myelination in human brain development. Cereb. Cortex 29, 827-837. https://doi.org/10.1093/cercor/bhy277.

Cao, B., Mwangi, B., Passos, I.C., Wu, M.-J., Keser, Z., Zunta-Soares, G.B., Xu, D., Hasan, K.M., Soares, J.C., 2017. Lifespan gyrification trajectories of human brain in healthy individuals and patients with major psychiatric disorders. Sci. Rep. 7, 511. https://doi.org/10.1038/s41598-017-00582-1.

Carlo, C.N., Stevens, C.F., 2013. Structural uniformity of neocortex, revisited. Proc. Natl. Acad. Sci. 110, 1488-1493. https://doi.org/10.1073/pnas.1221398110.

Casey, B., Tottenham, N., Liston, C., Durston, S., 2005. Imaging the developing brain: what have we learned about cognitive development? Trends Cogn. Sci. 9, 104-110. https://doi.org/10.1016/j.tics.2005.01.011.

Caviness, V., 1975. Mechanical model of brain convolutional development. Science 189, 18-21. https://doi.org/10.1126/science.1135626.

Chan, W.Y., Kostovic, I., Takashima, S., Feldhaus, C., Stoltenburg-Didinger, G., Verney, C., Yew, D., Ulfig, N., 2002. Normal and abnormal development of the human cerebral cortex. Neuroembryology 1, 78-90. https://doi.org/10.1159/ 000054267.

Chen, C.-H., Gutierrez, E.D., Thompson, W., Panizzon, M.S., Jernigan, T.L., Eyler, L.T., Fennema-Notestine, C., Jak, A.J., Neale, M.C., Franz, C.E., Lyons, M.J., Grant, M.D., Fischl, B., Seidman, L.J., Tsuang, M.T., Kremen, W.S., Dale, A.M., 2012. Hierarchical genetic organization of human cortical surface area. Science 335, 1634. https://doi. org/10.1126/science.1215330.

Chen, C.-H., Fiecas, M., Gutierrez, E.D., Panizzon, M.S., Eyler, L.T., Vuoksimaa, E., Thompson, W.K., Fennema-Notestine, C., Hagler, D.J., Jernigan, T.L., Neale, M.C., Franz, C.E., Lyons, M.J., Fischl, B., Tsuang, M.T., Dale, A.M., Kremen, W.S., 2013. Genetic topography of brain morphology. Proc. Natl. Acad. Sci. 110, 17089-17094. https://doi.org/10.1073/pnas.1308091110.

Choudhury, S., 2010. Culturing the adolescent brain: what can neuroscience learn from anthropology? Soc. Cogn. Affect. Neurosci. 5, 159-167. https://doi.org/10.1093/ scan/nsp030.

Chung, Y.S., Hyatt, C.J., Stevens, M.C., 2017. Adolescent maturation of the relationship between cortical gyrification and cognitive ability. NeuroImage 158, 319-331. https://doi.org/10.1016/j.neuroimage.2017.06.082.

Colson, E.R., Dworkin, P.H., 1997. Toddler development. Pediatr. Rev. 18, 255-259. https://doi.org/10.1542/pir.18-8-255.

Croteau-Chonka, E.C., Dean, D.C., Remer, J., Dirks, H., O'Muircheartaigh, J., Deoni, S.C. L., 2016. Examining the relationships between cortical maturation and white matter myelination throughout early childhood. NeuroImage 125, 413-421. https://doi. org/10.1016/j.neuroimage.2015.10.038.

Darmanis, S., Sloan, S.A., Zhang, Y., Enge, M., Caneda, C., Shuer, L.M., Hayden Gephart, M.G., Barres, B.A., Quake, S.R., 2015. A survey of human brain transcriptome diversity at the single cell level. Proc. Natl. Acad. Sci. 112, 7285-7290. https://doi.org/10.1073/pnas.1507125112.

Deoni, S.C.L., Dean, D.C., O'Muircheartaigh, J., Dirks, H., Jerskey, B.A., 2012. Investigating white matter development in infancy and early childhood using myelin water faction and relaxation time mapping. NeuroImage 63, 1038-1053. https://doi. org/10.1016/j.neuroimage.2012.07.037.

Deoni, S.C.L., Dean, D.C., Remer, J., Dirks, H., O'Muircheartaigh, J., 2015. Cortical maturation and myelination in healthy toddlers and young children. NeuroImage 115, 147-161. https://doi.org/10.1016/j.neuroimage.2015.04.058.

Desikan, R.S., Ségonne, F., Fischl, B., Quinn, B.T., Dickerson, B.C., Blacker, D., Buckner, R.L., Dale, A.M., Maguire, R.P., Hyman, B.T., Albert, M.S., Killiany, R.J. 2006. An automated labeling system for subdividing the human cerebral cortex on MRI scans into gyral based regions of interest. NeuroImage 31, 968-980. https://doi. org/10.1016/j.neuroimage.2006.01.021.

Destrieux, C., Fischl, B., Dale, A., Halgren, E., 2010. Automatic parcellation of human cortical gyri and sulci using standard anatomical nomenclature. NeuroImage 53, 1-15. https://doi.org/10.1016/j.neuroimage.2010.06.010.

Dick, A.S., Lopez, D.A., Watts, A.L., Heeringa, S., Reuter, C., Bartsch, H., Fan, C.C., Kennedy, D.N., Palmer, C., Marshall, A., Haist, F., Hawes, S., Nichols, T.E., Barch, D. M., Jernigan, T.L., Garavan, H., Grant, S., Pariyadath, V., Hoffman, E., Neale, M., Stuart, E.A., Paulus, M.P., Sher, K.J., Thompson, W.K., 2020. Meaningful associations in the adolescent brain cognitive development study (preprint). Neuroscience. https://doi.org/10.1101/2020.09.01.276451.

Doan, N.T., Engvig, A., Zaske, K., Persson, K., Lund, M.J., Kaufmann, T., CordovaPalomera, A., Alnæs, D., Moberget, T., Brækhus, A., Barca, M.L., Nordvik, J.E., Engedal, K., Agartz, I., Selbæk, G., Andreassen, O.A., Westlye, L.T., 2017. Distinguishing early and late brain aging from the Alzheimer's disease spectrum: consistent morphological patterns across independent samples. NeuroImage 158, 282-295. https://doi.org/10.1016/j.neuroimage.2017.06.070.

Does, M.D., 2018. Inferring brain tissue composition and microstructure via MR relaxometry. NeuroImage 182, 136-148. https://doi.org/10.1016/j. neuroimage.2017.12.087.

Drakulich, S., Thiffault, A.-C., Olafson, E., Parent, O., Labbe, A., Albaugh, M.D., Khundrakpam, B., Ducharme, S., Evans, A., Chakravarty, M.M., Karama, S., 2021. Maturational trajectories of pericortical contrast in typical brain development. NeuroImage 235, 117974. https://doi.org/10.1016/j.neuroimage.2021.117974.

Ducharme, S., Albaugh, M.D., Nguyen, T.-V., Hudziak, J.J., Mateos-Pérez, J.M., Labbe, A., Evans, A.C., Karama, S., 2015. Trajectories of cortical surface area and 
cortical volume maturation in normal brain development. Data Brief 5, 929-938. https://doi.org/10.1016/j.dib.2015.10.044.

Ducharme, S., Albaugh, M.D., Nguyen, T.-V., Hudziak, J.J., Mateos-Pérez, J.M., Labbe, A., Evans, A.C., Karama, S., Brain Development Cooperative Group, 2016. Trajectories of cortical thickness maturation in normal brain development-The importance of quality control procedures. NeuroImage 125, 267-279. https://doi. org/10.1016/j.neuroimage.2015.10.010.

Ehrlich, S., Brauns, S., Yendiki, A., Ho, B.-C., Calhoun, V., Schulz, S.C., Gollub, R.L., Sponheim, S.R., 2012. Associations of cortical thickness and cognition in patients with Schizophrenia and healthy controls. Schizophr. Bull. 38, 1050-1062. https:// doi.org/10.1093/schbul/sbr018.

Eickhoff, S., Walters, N.B., Schleicher, A., Kril, J., Egan, G.F., Zilles, K., Watson, J.D.G. Amunts, K., 2005. High-resolution MRI reflects myeloarchitecture and cytoarchitecture of human cerebral cortex. Hum. Brain Mapp. 24, 206-215. https:// doi.org/10.1002/hbm.20082.

Elias, H., Schwartz, D., 1969. Surface areas of the cerebral cortex of mammals determined by stereological methods. Science 166, 111-113. https://doi.org/ 10.1126/science.166.3901.111.

Fan, L., Li, H., Zhuo, J., Zhang, Y., Wang, J., Chen, L., Yang, Z., Chu, C., Xie, S., Laird, A. R., Fox, P.T., Eickhoff, S.B., Yu, C., Jiang, T., 2016. The human brainnetome atlas: a new brain atlas based on connectional architecture. Cereb. Cortex 26, 3508-3526. https://doi.org/10.1093/cercor/bhw157.

Fan, F., Liao, X., Lei, T., Zhao, T., Xia, M., Men, W., Wang, Y., Hu, M., Liu, J., Qin, S., Tan, S., Gao, J.-H., Dong, Q., Tao, S., He, Y., 2021. Development of the default-mode network during childhood and adolescence: A longitudinal resting-state fMRI study. NeuroImage 226, 117581, https://doi.org/10.1016/j.neuroimage.2020.117581.

Farah, M.J., 2017. The neuroscience of socioeconomic status: correlates, causes, and consequences. Neuron 96, 56-71. https://doi.org/10.1016/j.neuron.2017.08.034.

Fischl, B., 2012. FreeSurfer. NeuroImage 62, 774-781. https://doi.org/10.1016/j. neuroimage.2012.01.021.

Fischl, B., Dale, A.M., 2000. Measuring the thickness of the human cerebral cortex from magnetic resonance images. Proc. Natl. Acad. Sci. 97, 11050-11055. https://doi. org/10.1073/pnas.200033797.

Fischl, B., Sereno, M.I., Dale, A.M., 1999a. Cortical surface-based analysis. NeuroImage 9, 195-207. https://doi.org/10.1006/nimg.1998.0396.

Fischl, B., Sereno, M.I., Tootell, R.B.H., Dale, A.M., 1999b. High-resolution intersubject averaging and a coordinate system for the cortical surface. Hum. Brain Mapp. 8 , 272-284. https://doi.org/10.1002/(SICI)1097-0193(1999)8:4<272::AID HBM10>3.0.CO;2-4.

Fish, A.M., Cachia, A., Fischer, C., Mankiw, C., Reardon, P.K., Clasen, L.S., Blumenthal, J. D., Greenstein, D., Giedd, J.N., Mangin, J.-F., Raznahan, A., 2016. Influences of brain size, sex, and sex chromosome complement on the architecture of human cortical folding. Cereb. Cortex cercor. https://doi.org/10.1093/cercor/bhw323 bhw323v1.

Fjell, A.M., Grydeland, H., Krogsrud, S.K., Amlien, I., Rohani, D.A., Ferschmann, L., Storsve, A.B., Tamnes, C.K., Sala-Llonch, R., Due-Tønnessen, P., Bjørnerud, A., Sølsnes, A.E., Håberg, A.K., Skranes, J., Bartsch, H., Chen, C.-H., Thompson, W.K., Panizzon, M.S., Kremen, W.S., Dale, A.M., Walhovd, K.B., 2015. Development and aging of cortical thickness correspond to genetic organization patterns. Proc. Natl. Acad. Sci. 112, 15462-15467. https://doi.org/10.1073/pnas.1508831112.

Forde, N.J., Jeyachandra, J., Joseph, M., Jacobs, G.R., Dickie, E., Satterthwaite, T.D., Shinohara, R.T., Ameis, S.H., Voineskos, A.N., 2020. Sex differences in variability of brain structure across the Lifespan. Cereb. Cortex 30, 5420-5430. https://doi.org/ 10.1093/cercor/bhaa123.

Foulkes, L., Blakemore, S.-J., 2018. Studying individual differences in human adolescen brain development. Nat. Neurosci. 21, 315-323. https://doi.org/10.1038/s41593018-0078-4.

Frangou, S., Modabbernia, A., Doucet, G.E., Papachristou, E., Williams, S.C., Agartz, I., Aghajani, M., Akudjedu, T.N., Albajes-Eizagirre, A., Alnæs, D., Alpert, K.I., Andersson, M., Andreasen, N., Andreassen, O.A., Asherson, P., Banaschewski, T., Bargallo, N., Baumeister, S., Baur-Streubel, R., Bertolino, A., Bonvino, A., Boomsma, D.I., Borgwardt, S., Bourque, J., Brandeis, D., Breier, A., Brodaty, H., Brouwer, R.M., Buitelaar, J.K., Busatto, G.F., Buckner, R.L., Calhoun, V., CanalesRodríguez, E.J., Cannon, D.M., Caseras, X., Castellanos, F.X., Cervenka, S., ChaimAvancini, T.M., Ching, C.R., Clark, V.P., Conrod, P., Conzelmann, A., CrespoFacorro, B., Crivello, F., Crone, E.A., Dale, A.M., Davey, C., de Geus, E.J., de Haan, L., de Zubicaray, G.I., Braber, Aden, Dickie, E.W., Di Giorgio, A., Doan, N.T., Dørum, E.S., Ehrlich, S., Erk, S., Espeseth, T., Fatouros-Bergman, H., Fisher, S.E., Fouche, J.-P., Franke, B., Frodl, T., Fuentes-Claramonte, P., Glahn, D.C., Gotlib, I.H., Grabe, H.-J., Grimm, O., Groenewold, N.A., Grotegerd, D., Gruber, O., Gruner, P., Gur, R.E., Gur, R.C., Harrison, B.J., Hartman, C.A., Hatton, S.N., Heinz, A., Heslenfeld, D.J., Hibar, D.P., Hickie, I.B., Ho, B.-C., Hoekstra, P.J., Hohmann, S. Holmes, A.J., Hoogman, M., Hosten, N., Howells, F.M., Hulshoff Pol, H.E., Huyser, C., Jahanshad, N., James, A., Jiang, J., Jönsson, E.G., Joska, J.A., Kahn, R., Kalnin, A., Kanai, R., Kang, S., Klein, M., Klushnik, T.P., Koenders, L., Koops, S., Krämer, B., Kuntsi, J., Lagopoulos, J., Lázaro, L., Lebedeva, I., Lee, W.H., Lesch, K. P., Lochner, C., Machielsen, M.W., Maingault, S., Martin, N.G., Martínez-Zalacaín, I., Mataix-Cols, D., Mazoyer, B., McDonald, C., McDonald, B.C., McIntosh, A.M., McMahon, K.L., McPhilemy, G., Menchón, J.M., Medland, S.E., MeyerLindenberg, A., Naaijen, J., Najt, P., Nakao, T., Nordvik, J.E., Nyberg, L. Oosterlaan, J., de la Foz, V.O.-G., Paloyelis, Y., Pauli, P., Pergola, G., PomarolClotet, E., Portella, M.J., Potkin, S.G., Radua, J., Reif, A., Roffman, J.L., Rosa, P.G., Sacchet, M.D., Sachdev, P.S., Salvador, R., Sánchez-Juan, P., Sarró, S., Satterthwaite, T.D., Saykin, A.J., Serpa, M.H., Schmaal, L., Schnell, K., Schumann, G., Smoller, J.W., Sommer, I., Soriano-Mas, C., Stein, D.J., Strike, L.T., Swagerman, S.C., Tamnes, C.K., Temmingh, H.S., Thomopoulos, S.I., Tomyshev, A S., Tordesillas-Gutiérrez, D., Trollor, J.N., Turner, J.A., Uhlmann, A., van den
Heuvel, O.A., van den Meer, D., van der Wee, N.J., van Haren, N.E., van' t Ent, D., van Erp, T.G., Veer, I.M., Veltman, D.J., Völzke, H., Walter, H., Walton, E., Wang, L., Wang, Y., Wassink, T.H., Weber, B., Wen, W., West, J.D., Westlye, L.T., Whalley, H., Wierenga, L.M., Wittfeld, K., Wolf, D.H., Wright, M.J., Yang, K., Yoncheva, Y., Zanetti, M.V., Ziegler, G.C., Thompson, P.M., Dima, D., 2020. Cortical Thickness Trajectories across the Lifespan: data from 17,075 healthy individuals aged 3-90 years (preprint). Neuroscience. https://doi.org/10.1101/2020.05.05.077834.

French, L., Paus, T., 2015. A FreeSurfer view of the cortical transcriptome generated from the Allen Human Brain Atlas. Front. Neurosci. 9 https://doi.org/10.3389/ fnins.2015.00323.

Gao, W., Grewen, K., Knickmeyer, R.C., Qiu, A., Salzwedel, A., Lin, W., Gilmore, J.H., 2019. A review on neuroimaging studies of genetic and environmental influences on early brain development. NeuroImage 185, 802-812. https://doi.org/10.1016/j. neuroimage.2018.04.032.

Gennatas, E.D., Avants, B.B., Wolf, D.H., Satterthwaite, T.D., Ruparel, K., Ciric, R., Hakonarson, H., Gur, R.E., Gur, R.C., 2017. Age-related effects and sex differences in gray matter density, volume, mass, and cortical thickness from childhood to young adulthood. J. Neurosci. 37, 5065-5073. https://doi.org/10.1523/JNEUROSCI.355016.2017.

Giedd, J.N., Blumenthal, J., Jeffries, N.O., Castellanos, F.X., Liu, H., Zijdenbos, A. Paus, T., Evans, A.C., Rapoport, J.L., 1999. Brain development during childhood and adolescence: a longitudinal MRI study. Nat. Neurosci. 2, 861-863. https://doi.org/ $10.1038 / 13158$

Gilmore, J.H., Shi, F., Woolson, S.L., Knickmeyer, R.C., Short, S.J., Lin, W., Zhu, H., Hamer, R.M., Styner, M., Shen, D., 2012. Longitudinal development of cortical and subcortical gray matter from birth to 2 years. Cereb. Cortex 22, 2478-2485. https:// doi.org/10.1093/cercor/bhr327.

Gilmore, J.H., Knickmeyer, R.C., Gao, W., 2018. Imaging structural and functional brain development in early childhood. Nat. Rev. Neurosci. 19, 123-137. https://doi.org/ 10.1038/nrn.2018.1.

Gilmore, A.D., Buser, N.J., Hanson, J.L., 2021. Variations in structural MRI quality significantly impact commonly used measures of brain anatomy. Brain Inform. 8, 7. https://doi.org/10.1186/s40708-021-00128-2.

Ginsburg, K.R., the Committee on Communications, and the Committee on Psychosocial Aspects of Child and Family Health, 2007. The importance of play in promoting healthy child development and maintaining strong parent-child bonds. Pediatrics 119, 182-191. https://doi.org/10.1542/peds.2006-2697.

Glasser, M.F., Van Essen, D.C., 2011. Mapping human cortical areas in vivo based on myelin content as revealed by T1- and T2-Weighted MRI. J. Neurosci. 31, 11597-11616. https://doi.org/10.1523/JNEUROSCI.2180-11.2011.

Glasser, M.F., Coalson, T.S., Robinson, E.C., Hacker, C.D., Harwell, J., Yacoub, E. Ugurbil, K., Andersson, J., Beckmann, C.F., Jenkinson, M., Smith, S.M., Van Essen, D. C., 2016. A multi-modal parcellation of human cerebral cortex. Nature 536, 171-178. https://doi.org/10.1038/nature18933.

Gogtay, N., Giedd, J.N., Lusk, L., Hayashi, K.M., Greenstein, D., Vaituzis, A.C., Nugent, T. F., Herman, D.H., Clasen, L.S., Toga, A.W., Rapoport, J.L., Thompson, P.M., 2004 Dynamic mapping of human cortical development during childhood through early adulthood. Proc. Natl. Acad. Sci. 101, 8174-8179. https://doi.org/10.1073/ pnas.0402680101.

Goriounova, N.A., Heyer, D.B., Wilbers, R., Verhoog, M.B., Giugliano, M., Verbist, C., Obermayer, J., Kerkhofs, A., Smeding, H., Verberne, M., Idema, S., Baayen, J.C., Pieneman, A.W., de Kock, C.P., Klein, M., Mansvelder, H.D., 2018. Large and fast human pyramidal neurons associate with intelligence. eLife 7, e41714. https://doi. org/10.7554/eLife.41714.

Grasby, K.L., Jahanshad, N., Painter, J.N., Colodro-Conde, L., Bralten, J., Hibar, D.P., Lind, P.A., Pizzagalli, F., Ching, C.R.K., McMahon, M.A.B., Shatokhina, N., Zsembik, L.C.P., Thomopoulos, S.I., Zhu, A.H., Strike, L.T., Agartz, I., Alhusaini, S., Almeida, M.A.A., Alnæs, D., Amlien, I.K., Andersson, M., Ard, T., Armstrong, N.J., Ashley-Koch, A., Atkins, J.R., Bernard, M., Brouwer, R.M., Buimer, E.E.L., Bülow, R., Bürger, C., Cannon, D.M., Chakravarty, M., Chen, Q., Cheung, J.W., CouvyDuchesne, B., Dale, A.M., Dalvie, S., de Araujo, T.K., de Zubicaray, G.I., de Zwarte, S. M.C., den Braber, A., Doan, N.T., Dohm, K., Ehrlich, S., Engelbrecht, H.-R., Erk, S., Fan, C.C., Fedko, I.O., Foley, S.F., Ford, J.M., Fukunaga, M., Garrett, M.E., Ge, T., Giddaluru, S., Goldman, A.L., Green, M.J., Groenewold, N.A., Grotegerd, D., Gurholt, T.P., Gutman, B.A., Hansell, N.K., Harris, M.A., Harrison, M.B., Haswell, C. C., Hauser, M., Herms, S., Heslenfeld, D.J., Ho, N.F., Hoehn, D., Hoffmann, P., Holleran, L., Hoogman, M., Hottenga, J.-J., Ikeda, M., Janowitz, D., Jansen, I.E., Jia, T., Jockwitz, C., Kanai, R., Karama, S., Kasperaviciute, D., Kaufmann, T., Kelly, S., Kikuchi, M., Klein, M., Knapp, M., Knodt, A.R., Krämer, B., Lam, M. Lancaster, T.M., Lee, P.H., Lett, T.A., Lewis, L.B., Lopes-Cendes, I., Luciano, M., Macciardi, F., Marquand, A.F., Mathias, S.R., Melzer, T.R., Milaneschi, Y., MirzaSchreiber, N., Moreira, J.C.V., Mühleisen, T.W., Müller-Myhsok, B., Najt, P., Nakahara, S., Nho, K., Olde Loohuis, L.M., Orfanos, D.P., Pearson, J.F., Pitcher, T.L., Pütz, B., Quidé, Y., Ragothaman, A., Rashid, F.M., Reay, W.R., Redlich, R., Reinbold, C.S., Repple, J., Richard, G., Riedel, B.C., Risacher, S.L., Rocha, C.S., Mota, N.R., Salminen, L., Saremi, A., Saykin, A.J., Schlag, F., Schmaal, L Schofield, P.R., Secolin, R., Shapland, C.Y., Shen, L., Shin, J., Shumskaya, E., Sønderby, I.E., Sprooten, E., Tansey, K.E., Teumer, A., Thalamuthu, A., TordesillasGutiérrez, D., Turner, J.A., Uhlmann, A., Vallerga, C.L., van der Meer, D., van Donkelaar, M.M.J., van Eijk, L., van Erp, T.G.M., van Haren, N.E.M., van Rooij, D., van Tol, M.-J., Veldink, J.H., Verhoef, E., Walton, E., Wang, M., Wang, Y., Wardlaw, J.M., Wen, W., Westlye, L.T., Whelan, C.D., Witt, S.H., Wittfeld, K. Wolf, C., Wolfers, T., Wu, J.Q., Yasuda, C.L., Zaremba, D., Zhang, Z., Zwiers, M.P., Artiges, E., Assareh, A.A., Ayesa-Arriola, R., Belger, A., Brandt, C.L., Brown, G.G., Cichon, S., Curran, J.E., Davies, G.E., Degenhardt, F., Dennis, M.F., Dietsche, B., Djurovic, S., Doherty, C.P., Espiritu, R., Garijo, D., Gil, Y., Gowland, P.A., Green, R. 
C., Häusler, A.N., Heindel, W., Ho, B.-C., Hoffmann, W.U., Holsboer, F., Homuth, G., Hosten, N., Jack, C.R., Jang, M., Jansen, A., Kimbrel, N.A., Kolskår, K., Koops, S., Krug, A., Lim, K.O., Luykx, J.J., Mathalon, D.H., Mather, K.A., Mattay, V.S., Matthews, S., Mayoral Van Son, J., McEwen, S.C., Melle, I., Morris, D.W., Mueller, B. A., Nauck, M., Nordvik, J.E., Nöthen, M.M., O'Leary, D.S., Opel, N., Martinot, M.-L. P., Pike, G.B., Preda, A., Quinlan, E.B., Rasser, P.E., Ratnakar, V., Reppermund, S., Steen, V.M., Tooney, P.A., Torres, F.R., Veltman, D.J., Voyvodic, J.T., Whelan, R., White, T., Yamamori, H., Adams, H.H.H., Bis, J.C., Debette, S., Decarli, C., Fornage, M., Gudnason, V., Hofer, E., Ikram, M.A., Launer, L., Longstreth, W.T., Lopez, O.L., Mazoyer, B., Mosley, T.H., Roshchupkin, G.V., Satizabal, C.L., Schmidt, R., Seshadri, S., Yang, Q., Alvim, M.K.M., Ames, D., Anderson, T.J., Andreassen, O.A., Arias-Vasquez, A., Bastin, M.E., Baune, B.T., Beckham, J.C., Blangero, J., Boomsma, D.I., Brodaty, H., Brunner, H.G., Buckner, R.L., Buitelaar, J. K., Bustillo, J.R., Cahn, W., Cairns, M.J., Calhoun, V., Carr, V.J., Caseras, X., Caspers, S., Cavalleri, G.L., Cendes, F., Corvin, A., Crespo-Facorro, B., DalrympleAlford, J.C., Dannlowski, U., de Geus, E.J.C., Deary, I.J., Delanty, N., Depondt, C., Desrivières, S., Donohoe, G., Espeseth, T., Fernández, G., Fisher, S.E., Flor, H., Forstner, A.J., Francks, C., Franke, B., Glahn, D.C., Gollub, R.L., Grabe, H.J., Gruber, O., Håberg, A.K., Hariri, A.R., Hartman, C.A., Hashimoto, R., Heinz, A., Henskens, F.A., Hillegers, M.H.J., Hoekstra, P.J., Holmes, A.J., Hong, L.E., Hopkins, W.D., Hulshoff Pol, H.E., Jernigan, T.L., Jönsson, E.G., Kahn, R.S., Kennedy, M.A., Kircher, T.T.J., Kochunov, P., Kwok, J.B.J., Le Hellard, S., Loughland, C.M., Martin, N.G., Martinot, J.-L., McDonald, C., McMahon, K.L., Meyer-Lindenberg, A., Michie, P.T., Morey, R.A., Mowry, B., Nyberg, L., Oosterlaan, J., Ophoff, R.A., Pantelis, C., Paus, T., Pausova, Z., Penninx, B.W.J.H., Polderman, T.J.C., Posthuma, D., Rietschel, M., Roffman, J.L., Rowland, L.M., Sachdev, P.S., Sämann, P.G., Schall, U., Schumann, G., Scott, R.J., Sim, K., Sisodiya, S.M., Smoller, J.W., Sommer, I.E., St Pourcain, B., Stein, D.J., Toga, A.W., Trollor, J.N., Van der Wee, N.J.A., van' t Ent, D., Völzke, H., Walter, H., Weber, B., Weinberger, D.R., Wright, M.J., Zhou, J., Stein, J.L., Thompson, P.M., Medland, S.E. 2020. The genetic architecture of the human cerebral cortex. Science 367, eaay6690. https://doi.org/10.1126/science.aay6690.

Grydeland, H., Walhovd, K.B., Tamnes, C.K., Westlye, L.T., Fjell, A.M., 2013. Intracortical myelin links with performance variability across the human lifespan: results from T1- and T2-Weighted MRI myelin mapping and diffusion tensor imaging. J. Neurosci. 33, 18618-18630. https://doi.org/10.1523/ JNEUROSCI.2811-13.2013.

Grydeland, H., Vértes, P.E., Váša, F., Romero-Garcia, R., Whitaker, K., AlexanderBloch, A.F., Bjørnerud, A., Patel, A.X., Sederevičius, D., Tamnes, C.K., Westlye, L.T., White, S.R., Walhovd, K.B., Fjell, A.M., Bullmore, E.T., 2019. Waves of maturation and senescence in micro-structural MRI markers of human cortical myelination over the lifespan. Cereb. Cortex 29, 1369-1381. https://doi.org/10.1093/cercor/bhy330.

Häfner, H., Maurer, K., Löffler, W., Riecher-Rössler, A., 1993. The influence of age and sex on the onset and early course of schizophrenia. Br. J. Psychiatry 162, 80-86. https://doi.org/10.1192/bjp.162.1.80.

Hagiwara, A., Hori, M., Kamagata, K., Warntjes, M., Matsuyoshi, D., Nakazawa, M., Ueda, R., Andica, C., Koshino, S., Maekawa, T., Irie, R., Takamura, T., Kumamaru, K. K., Abe, O., Aoki, S., 2018. Myelin Measurement: Comparison Between Simultaneous Tissue Relaxometry, Magnetization Transfer Saturation Index, and T1w/T2w Ratio Methods. Sci. Rep. 8, 10554. https://doi.org/10.1038/s41598-018-28852-6.

Harris, K.D., Shepherd, G.M.G., 2015. The neocortical circuit: themes and variations. Nat. Neurosci. 18, 170-181. https://doi.org/10.1038/nn.3917.

Hawrylycz, M.J., Lein, E.S., Guillozet-Bongaarts, A.L., Shen, E.H., Ng, L., Miller, J.A., van de Lagemaat, L.N., Smith, K.A., Ebbert, A., Riley, Z.L., Abajian, C., Beckmann, C.F., Bernard, A., Bertagnolli, D., Boe, A.F., Cartagena, P.M., Chakravarty, M.M., Chapin, M., Chong, J., Dalley, R.A., Daly, B.D., Dang, C., Datta, S., Dee, N., Dolbeare, T.A., Faber, V., Feng, D., Fowler, D.R., Goldy, J., Gregor, B.W., Haradon, Z., Haynor, D.R., Hohmann, J.G., Horvath, S., Howard, R.E., Jeromin, A., Jochim, J.M., Kinnunen, M., Lau, C., Lazarz, E.T., Lee, C., Lemon, T.A., Li, L., Li, Y., Morris, J.A., Overly, C.C., Parker, P.D., Parry, S.E., Reding, M., Royall, J.J., Schulkin, J., Sequeira, P.A., Slaughterbeck, C.R., Smith, S.C., Sodt, A.J., Sunkin, S. M., Swanson, B.E., Vawter, M.P., Williams, D., Wohnoutka, P., Zielke, H.R., Geschwind, D.H., Hof, P.R., Smith, S.M., Koch, C., Grant, S.G.N., Jones, A.R., 2012 An anatomically comprehensive atlas of the adult human brain transcriptome. Nature 489, 391-399. https://doi.org/10.1038/nature11405.

Hawrylycz, M., Miller, J.A., Menon, V., Feng, D., Dolbeare, T., Guillozet-Bongaarts, A.L., Jegga, A.G., Aronow, B.J., Lee, C.-K., Bernard, A., Glasser, M.F., Dierker, D.L., Menche, J., Szafer, A., Collman, F., Grange, P., Berman, K.A., Mihalas, S., Yao, Z., Stewart, L., Barabási, A.-L., Schulkin, J., Phillips, J., Ng, L., Dang, C., Haynor, D.R., Jones, A., Van Essen, D.C., Koch, C., Lein, E., 2015. Canonical genetic signatures of the adult human brain. Nat. Neurosci. 18, 1832-1844. https://doi.org/10.1038/ nn. 4171.

Herting, M.M., Sowell, E.R., 2017. Puberty and structural brain development in humans. Front. Neuroendocrinol. 44, 122-137. https://doi.org/10.1016/j. yfrne.2016.12.003.

Hill, J., Inder, T., Neil, J., Dierker, D., Harwell, J., Van Essen, D.C., 2010. Similar patterns of cortical expansion during human development and evolution. Proc. Natl. Acad. Sci. 107, 13135-13140. https://doi.org/10.1073/pnas.1001229107.

Hofer, E., Roshchupkin, G.V., Adams, H.H.H., Knol, M.J., Lin, H., Li, S., Zare, H., Ahmad, S., Armstrong, N.J., Satizabal, C.L., Bernard, M., Bis, J.C., Gillespie, N.A., Luciano, M., Mishra, A., Scholz, M., Teumer, A., Xia, R., Jian, X., Mosley, T.H., Saba, Y., Pirpamer, L., Seiler, S., Becker, J.T., Carmichael, O., Rotter, J.I., Psaty, B. M., Lopez, O.L., Amin, N., van der Lee, S.J., Yang, Q., Himali, J.J., Maillard, P., Beiser, A.S., DeCarli, C., Karama, S., Lewis, L., Harris, M., Bastin, M.E., Deary, I.J., Veronica Witte, A., Beyer, F., Loeffler, M., Mather, K.A., Schofield, P.R., Thalamuthu, A., Kwok, J.B., Wright, M.J., Ames, D., Trollor, J., Jiang, J.,
Brodaty, H., Wen, W., Vernooij, M.W., Hofman, A., Uitterlinden, A.G., Niessen, W.J., Wittfeld, K., Bülow, R., Völker, U., Pausova, Z., Bruce Pike, G., Maingault, S., Crivello, F., Tzourio, C., Amouyel, P., Mazoyer, B., Neale, M.C., Franz, C.E., Lyons, M.J., Panizzon, M.S., Andreassen, O.A., Dale, A.M., Logue, M., Grasby, K.L., Jahanshad, N., Painter, J.N., Colodro-Conde, L., Bralten, J., Hibar, D.P., Lind, P.A., Pizzagalli, F., Stein, J.L., Thompson, P.M., Medland, S.E., Sachdev, P.S., Kremen, W. S., Wardlaw, J.M., Villringer, A., van Duijn, C.M., Grabe, H.J., Longstreth, W.T., Fornage, M., Paus, T., Debette, S., Arfan Ikram, M., Schmidt, H., Schmidt, R., Seshadri, S., ENIGMA consortium, 2020. Genetic correlations and genome-wide associations of cortical structure in general population samples of 22,824 adults. Nat. Commun. 11 https://doi.org/10.1038/s41467-020-18367-y.

Hogstrom, L.J., Westlye, L.T., Walhovd, K.B., Fjell, A.M., 2013. The Structure of the Cerebral Cortex Across Adult Life: Age-Related Patterns of Surface Area, Thickness, and Gyrification. Cereb. Cortex 23, 2521-2530. https://doi.org/10.1093/cercor/ bhs 231 .

Hooker, C.I., Bruce, L., Lincoln, S.H., Fisher, M., Vinogradov, S., 2011. Theory of mind skills are related to gray matter volume in the ventromedial prefrontal cortex in schizophrenia. Biol. Psychiatry 70, 1169-1178. https://doi.org/10.1016/j. biopsych.2011.07.027.

Huttenlocher, P.R., 1979. Synaptic density in human frontal cortex - developmental changes and effects of aging. Brain Res. 163, 195-205. https://doi.org/10.1016/ 0006-8993(79)90349-4.

Huttenlocher, P.R., Dabholkar, A.S., 1997. Regional differences in synaptogenesis in human cerebral cortex. J. Comp. Neurol. 387, 167-178. https://doi.org/10.1002/ (SICI)1096-9861(19971020)387:2<167::AID-CNE1>3.0.CO;2-Z.

Jahanshad, N., Thompson, P.M., 2017. Multimodal neuroimaging of male and female brain structure in health and disease across the life span: Multimodal Neuroimaging of Brain Structure. J. Neurosci. Res. 95, 371-379. https://doi.org/10.1002/ jnr.23919.

Jha, S.C., Xia, K., Ahn, M., Girault, J.B., Li, G., Wang, L., Shen, D., Zou, F., Zhu, H., Styner, M., Gilmore, J.H., Knickmeyer, R.C., 2019. Environmental influences on infant cortical thickness and surface area. Cereb. Cortex 29, 1139-1149. https://doi. org/10.1093/cercor/bhy020.

Joel, D., Berman, Z., Tavor, I., Wexler, N., Gaber, O., Stein, Y., Shefi, N., Pool, J., Urchs, S., Margulies, D.S., Liem, F., Hänggi, J., Jäncke, L., Assaf, Y., 2015. Sex beyond the genitalia: the human brain mosaic. Proc. Natl. Acad. Sci. 112, 15468-15473. https://doi.org/10.1073/pnas.1509654112.

Jørgensen, K.N., Nerland, S., Norbom, L.B., Doan, N.T., Nesvåg, R., Mørch-Johnsen, L., Haukvik, U.K., Melle, I., Andreassen, O.A., Westlye, L.T., Agartz, I., 2016. Increased MRI-based cortical grey/white-matter contrast in sensory and motor regions in schizophrenia and bipolar disorder. Psychol. Med. 46, 1971-1985. https://doi.org/ 10.1017/S0033291716000593.

Jones, C.M., Braithwaite, V.A., Healy, S.D., 2003. The evolution of sex differences in spatial ability. Behav. Neurosci. 117, 403-411. https://doi.org/10.1037/07357044.117.3.403.

Kaczkurkin, A.N., Raznahan, A., Satterthwaite, T.D., 2019. Sex differences in the developing brain: insights from multimodal neuroimaging. Neuropsychopharmacology 44, 71-85. https://doi.org/10.1038/s41386-018-0111z.

Kang, H.J., Kawasawa, Y.I., Cheng, F., Zhu, Y., Xu, X., Li, M., Sousa, A.M.M., Pletikos, M., Meyer, K.A., Sedmak, G., Guennel, T., Shin, Y., Johnson, M.B., Krsnik, Ž., Mayer, S., Fertuzinhos, S., Umlauf, S., Lisgo, S.N., Vortmeyer, A., Weinberger, D.R., Mane, S., Hyde, T.M., Huttner, A., Reimers, M., Kleinman, J.E., Šestan, N., 2011. Spatiotemporal transcriptome of the human brain. Nature 478, 483-489. https://doi.org/ 10.1038/nature10523.

Kessler, R.C., Berglund, P., Demler, O., Jin, R., Merikangas, K.R., Walters, E.E., 2005. Lifetime prevalence and age-of-Onset distributions of DSM-IV disorders in the national comorbidity survey replication. Arch. Gen. Psychiatry 62, 593. https://doi. org/10.1001/archpsyc.62.6.593.

Kettenmann, H., Kirchhoff, F., Verkhratsky, A., 2013. Microglia: new roles for the synaptic stripper. Neuron 77, 10-18. https://doi.org/10.1016/j. neuron.2012.12.023.

Khundrakpam, B.S., Lewis, J.D., Reid, A., Karama, S., Zhao, L., Chouinard-Decorte, F., Evans, A.C., 2017. Imaging structural covariance in the development of intelligence. NeuroImage 144, 227-240. https://doi.org/10.1016/j.neuroimage.2016.08.041.

Khundrakpam, B.S., Lewis, J.D., Jeon, S., Kostopoulos, P., Itturia Medina, Y., ChouinardDecorte, F., Evans, A.C., 2019. Exploring individual brain variability during development based on patterns of maturational coupling of cortical thickness: a longitudinal MRI study. Cereb. Cortex 29, 178-188. https://doi.org/10.1093/ cercor/bhx317.

Klein, D., Rotarska-Jagiela, A., Genc, E., Sritharan, S., Mohr, H., Roux, F., Han, C.E., Kaiser, M., Singer, W., Uhlhaas, P.J., 2014. Adolescent brain maturation and cortical folding: evidence for reductions in gyrification. PLoS One 9, e84914. https://doi. org/10.1371/journal.pone.0084914.

Koenderink, M.J.Th., Uylings, H.B.M., 1995. Postnatal maturation of layer V pyramidal neurons in the human prefrontal cortex. A quantitative Golgi analysis. Brain Res. 678, 233-243. https://doi.org/10.1016/0006-8993(95)00206-6.

Koenderink, M.J.Th., Uylings, H.B.M., Mrzljak, L., 1994. Postnatal maturation of the layer III pyramidal neurons in the human prefrontal cortex: a quantitative Golgi analysis. Brain Res. 653, 173-182. https://doi.org/10.1016/0006-8993(94)90387. 5.

Koenig, S.H., 1991. Cholesterol of myelin is the determinant of gray-white contrast in MRI of brain. Magn. Reson. Med. 20, 285-291. https://doi.org/10.1002/ mrm.1910200210. 
Koenig, S.H., Brown, R.D., Spiller, M., Lundbom, N., 1990. Relaxometry of brain: why white matter appears bright in MRI. Magn. Reson. Med. 14, 482-495. https://doi. org/10.1002/mrm.1910140306.

Kostović, I., 2020. The enigmatic fetal subplate compartment forms an early tangential cortical nexus and provides the framework for construction of cortical connectivity. Prog. Neurobiol. 194, 101883 https://doi.org/10.1016/j.pneurobio.2020.101883.

Lake, B.B., Chen, S., Sos, B.C., Fan, J., Kaeser, G.E., Yung, Y.C., Duong, T.E., Gao, D., Chun, J., Kharchenko, P.V., Zhang, K., 2018. Integrative single-cell analysis of transcriptional and epigenetic states in the human adult brain. Nat. Biotechnol. 36, 70-80. https://doi.org/10.1038/nbt.4038.

Laule, C., Leung, E., Li, D.K., Traboulsee, A.L., Paty, D.W., MacKay, A.L., Moore, G.R., 2006. Myelin water imaging in multiple sclerosis: quantitative correlations with histopathology. Mult. Scler. J. 12, 747-753. https://doi.org/10.1177/ 1352458506070928.

Laule, C., Kozlowski, P., Leung, E., Li, D.K.B., MacKay, A.L., Moore, G.R.W., 2008. Myelin water imaging of multiple sclerosis at $7 \mathrm{~T}$ : correlations with histopathology. NeuroImage 40, 1575-1580. https://doi.org/10.1016/j.neuroimage.2007.12.008.

Lazari, A., Lipp, I., 2021. Can MRI measure myelin? Systematic review, qualitative assessment, and meta-analysis of studies validating microstructural imaging with myelin histology. NeuroImage 230, 117744. https://doi.org/10.1016/j. neuroimage.2021.117744.

Lebel, C., Deoni, S., 2018. The development of brain white matter microstructure. NeuroImage 182, 207-218. https://doi.org/10.1016/j.neuroimage.2017.12.097.

Lenroot, R.K., Gogtay, N., Greenstein, D.K., Wells, E.M., Wallace, G.L., Clasen, L.S., Blumenthal, J.D., Lerch, J., Zijdenbos, A.P., Evans, A.C., Thompson, P.M., Giedd, J. N., 2007. Sexual dimorphism of brain developmental trajectories during childhood and adolescence. NeuroImage 36, 1065-1073. https://doi.org/10.1016/j. neuroimage.2007.03.053.

Lerch, J.P., Worsley, K., Shaw, W.P., Greenstein, D.K., Lenroot, R.K., Giedd, J., Evans, A. C., 2006. Mapping anatomical correlations across cerebral cortex (MACACC) using cortical thickness from MRI. NeuroImage 31, 993-1003. https://doi.org/10.1016/j neuroimage.2006.01.042.

Lerch, J.P., van der Kouwe, A.J.W., Raznahan, A., Paus, T., Johansen-Berg, H., Miller, K. L., Smith, S.M., Fischl, B., Sotiropoulos, S.N., 2017. Studying neuroanatomy using MRI. Nat. Neurosci. 20, 314-326. https://doi.org/10.1038/nn.4501.

Lewis, J.D., Evans, A.C., Tohka, J., 2018. T1 white/gray contrast as a predictor of chronological age, and an index of cognitive performance. NeuroImage 173 341-350. https://doi.org/10.1016/j.neuroimage.2018.02.050.

Lewitus, E., Kelava, I., Kalinka, A.T., Tomancak, P., Huttner, W.B., 2016. Comment on "Cortical folding scales universally with surface area and thickness, not number of neurons.”. Science 351. https://doi.org/10.1126/science.aad2029, 825-825.

Li, G., Nie, J., Wang, L., Shi, F., Lin, W., Gilmore, J.H., Shen, D., 2013. Mapping regionspecific longitudinal cortical surface expansion from birth to 2 years of age. Cereb. Cortex 23, 2724-2733. https://doi.org/10.1093/cercor/bhs265.

Li, G., Wang, L., Shi, F., Lyall, A.E., Lin, W., Gilmore, J.H., Shen, D., 2014. Mapping longitudinal development of local cortical gyrification in infants from birth to 2 years of age. J. Neurosci. 34, 4228-4238. https://doi.org/10.1523/ JNEUROSCI.3976-13.2014.

Li, G., Lin, W., Gilmore, J.H., Shen, D., 2015. Spatial patterns, longitudinal development, and hemispheric asymmetries of cortical thickness in infants from birth to 2 years of age. J. Neurosci. 35, 9150-9162. https://doi.org/10.1523/JNEUROSCI.410714.2015.

Li, M., Santpere, G., Imamura Kawasawa, Y., Evgrafov, O.V., Gulden, F.O., Pochareddy, S., Sunkin, S.M., Li, Z., Shin, Y., Zhu, Y., Sousa, A.M.M., Werling, D.M., Kitchen, R.R., Kang, H.J., Pletikos, M., Choi, J., Muchnik, S., Xu, X., Wang, D. Lorente-Galdos, B., Liu, S., Giusti-Rodríguez, P., Won, H., de Leeuw, C.A., Pardiñas, A.F., BrainSpan Consortium, PsychENCODE Consortium, PsychENCODE Developmental Subgroup, Hu, M., Jin, F., Li, Y., Owen, M.J., O’Donovan, M.C., Walters, J.T.R., Posthuma, D., Reimers, M.A., Levitt, P., Weinberger, D.R., Hyde, T. M., Kleinman, J.E., Geschwind, D.H., Hawrylycz, M.J., State, M.W., Sanders, S.J., Sullivan, P.F., Gerstein, M.B., Lein, E.S., Knowles, J.A., Sestan, N., 2018. Integrative functional genomic analysis of human brain development and neuropsychiatric risks. Science 362, eaat7615. https://doi.org/10.1126/science.aat7615.

Lyall, A.E., Shi, F., Geng, X., Woolson, S., Li, G., Wang, L., Hamer, R.M., Shen, D., Gilmore, J.H., 2015. Dynamic development of regional cortical thickness and surface area in early childhood. Cereb. Cortex 25, 2204-2212. https://doi.org/10.1093/ cercor/bhu027.

Mackay, A., Whittall, K., Adler, J., Li, D., Paty, D., Graeb, D., 1994. In vivo visualization of myelin water in brain by magnetic resonance. Magn. Reson. Med. 31, 673-677. https://doi.org/10.1002/mrm.1910310614.

Madan, C.R., 2019. Robust estimation of sulcal morphology. Brain Inform. 6, 5. https:// doi.org/10.1186/s40708-019-0098-1.

Maere, S., Heymans, K., Kuiper, M., 2005. BiNGO: a Cytoscape plugin to assess overrepresentation of Gene Ontology categories in Biological Networks. Bioinformatics 21, 3448-3449. https://doi.org/10.1093/bioinformatics/bti551.

Magnaldi, S., Ukmar, M., Vasciaveo, A., Longo, R., Pozzi-Mucelli, R.S., 1993. Contrast between white and grey matter: MRI appearance with ageing. Eur. Radiol. 3 https:// doi.org/10.1007/BF00169600.

Makropoulos, A., Counsell, S.J., Rueckert, D., 2018. A review on automatic fetal and neonatal brain MRI segmentation. NeuroImage 170, 231-248. https://doi.org/ 10.1016/j.neuroimage.2017.06.074.

Marshall, W.A., Tanner, J.M., 1969. Variations in pattern of pubertal changes in girls. Arch. Dis. Child. 44, 291-303. https://doi.org/10.1136/adc.44.235.291.

Marshall, W.A., Tanner, J.M., 1970. Variations in the pattern of pubertal changes in boys. Arch. Dis. Child. 45, 13-23. https://doi.org/10.1136/adc.45.239.13.
Marx, M., Qi, G., Hanganu-Opatz, I.L., Kilb, W., Luhmann, H.J., Feldmeyer, D., 2015. Neocortical layer 6B as a remnant of the subplate - a morphological comparison. Cereb. Cortex bhv279. https://doi.org/10.1093/cercor/bhv279.

McMurray, B., 2007. Defusing the childhood vocabulary explosion. Science 317, 631. https://doi.org/10.1126/science.1144073.

Miller, D.J., Duka, T., Stimpson, C.D., Schapiro, S.J., Baze, W.B., McArthur, M.J., Fobbs, A.J., Sousa, A.M.M., Sestan, N., Wildman, D.E., Lipovich, L., Kuzawa, C.W., Hof, P.R., Sherwood, C.C., 2012. Prolonged myelination in human neocortical evolution. Proc. Natl. Acad. Sci. 109, 16480-16485. https://doi.org/10.1073/ pnas.1117943109.

Mills, K.L., Tamnes, C.K., 2014. Methods and considerations for longitudinal structural brain imaging analysis across development. Dev. Cogn. Neurosci. 9, 172-190. https://doi.org/10.1016/j.dcn.2014.04.004.

Mills, K.L., Tamnes, C.K., 2020. Longitudinal structural and functional brain development in childhood and adolescence. In: Cohen Kadosh, K. (Ed.), The Oxford Handbook of Developmental Cognitive Neuroscience. Oxford University Press. https://doi.org/10.1093/oxfordhb/9780198827474.013.4.

Mills, K.L., Lalonde, F., Clasen, L.S., Giedd, J.N., Blakemore, S.-J., 2014. Developmental changes in the structure of the social brain in late childhood and adolescence. Soc. Cogn. Affect. Neurosci. 9, 123-131. https://doi.org/10.1093/scan/nss113.

Mills, K.L., Goddings, A.-L., Herting, M.M., Meuwese, R., Blakemore, S.-J., Crone, E.A., Dahl, R.E., Güroğlu, B., Raznahan, A., Sowell, E.R., Tamnes, C.K., 2016. Structural brain development between childhood and adulthood: convergence across four longitudinal samples. NeuroImage 141, 273-281. https://doi.org/10.1016/j. neuroimage.2016.07.044.

Mills, K.L., Siegmund, K.D., Tamnes, C.K., Ferschmann, L., Wierenga, L.M., Bos, M.G.N., Luna, B., Herting, M.M., 2021. Individual variability in structural brain development from late childhood to young adulthood (preprint). Neuroscience. https://doi.org/ 10.1101/2021.02.04.429671.

Miot-Noirault, E., Barantin, L., Akoka, S., Le Pape, A., 1997. T2 relaxation time as a marker of brain myelination: experimental MR study in two neonatal animal models. J. Neurosci. Methods 72, 5-14. https://doi.org/10.1016/S0165-0270(96)00148-3.

Miquelajáuregui, A., Varela-Echavarría, A., 2008. Genetic control of Cajal-Retzius cell development. In: Ribak, C.E., de la Hoz, C.A., Jones, E.G., Larriva Sahd, J.A., Swanson, L.W. (Eds.), From Development to Degeneration and Regeneration of the Nervous System. Oxford University Press, pp. 45-68. https://doi.org/10.1093/ acprof:oso/9780195369007.003.0003.

Molnár, Z., Luhmann, H.J., Kanold, P.O., 2020. Transient cortical circuits match spontaneous and sensory-driven activity during development. Science 370 , eabb2153. https://doi.org/10.1126/science.abb2153.

Mota, B., Herculano-Houzel, S., 2015. Cortical folding scales universally with surface area and thickness, not number of neurons. Science 349, 74-77. https://doi.org/ 10.1126/science.aaa9101.

Mountcastle, V., 1995. The evolution of ideas concerning the function of the neocortex. Cereb. Cortex 5, 289-295. https://doi.org/10.1093/cercor/5.4.289.

Mrzljak, L., Uylings, H.B.M., Van Eden, G.G., Judáš, M., 1991. Chapter 9 neuronal development in human prefrontal cortex in prenatal and postnatal stages. Progress in Brain Research. Elsevier, pp. 185-222. https://doi.org/10.1016/S0079-6123(08) 62681-3.

Mutlu, A.K., Schneider, M., Debbané, M., Badoud, D., Eliez, S., Schaer, M., 2013. Sex differences in thickness, and folding developments throughout the cortex. NeuroImage 82, 200-207. https://doi.org/10.1016/j.neuroimage.2013.05.076.

Nakamura, K., Chen, J.T., Ontaneda, D., Fox, R.J., Trapp, B.D., 2017. T1-/T2-weighted ratio differs in demyelinated cortex in multiple sclerosis: T1-/T2-Weighted Ratio in MS. Ann. Neurol. 82, 635-639. https://doi.org/10.1002/ana.25019.

Natu, V.S., Gomez, J., Barnett, M., Jeska, B., Kirilina, E., Jaeger, C., Zhen, Z., Cox, S., Weiner, K.S., Weiskopf, N., Grill-Spector, K., 2019. Apparent thinning of human visual cortex during childhood is associated with myelination. Proc. Natl. Acad. Sci. 116, 20750-20759. https://doi.org/10.1073/pnas.1904931116.

Nieuwenhuys, R., 2013. The myeloarchitectonic studies on the human cerebral cortex of the Vogt-Vogt school, and their significance for the interpretation of functional neuroimaging data. Brain Struct. Funct. 218, 303-352. https://doi.org/10.1007/ s00429-012-0460-z.

Noble, K.G., Giebler, M.A., 2020. The neuroscience of socioeconomic inequality. Curr. Opin. Behav. Sci. 36, 23-28. https://doi.org/10.1016/j.cobeha.2020.05.007.

Norbom, L.B., Doan, N.T., Alnæs, D., Kaufmann, T., Moberget, T., Rokicki, J., Andreassen, O.A., Westlye, L.T., Tamnes, C.K., 2019. Probing Brain Developmental Patterns of Myelination and Associations With Psychopathology in Youths Using Gray/White Matter Contrast. Biol. Psychiatry 85, 389-398. https://doi.org/ 10.1016/j.biopsych.2018.09.027.

Norbom, L.B., Rokicki, J., Alnaes, D., Kaufmann, T., Doan, N.T., Andreassen, O.A., Westlye, L.T., Tamnes, C.K., 2020a. Maturation of cortical microstructure and cognitive development in childhood and adolescence: a T1w/T2w ratio MRI study. Hum. Brain Mapp. https://doi.org/10.1002/hbm.25149.

Norbom, L.B., Rokicki, J., van der Meer, D., Alnæs, D., Doan, N.T., Moberget, T., Kaufmann, T., Andreassen, O.A., Westlye, L.T., Tamnes, C.K., 2020b. Testing relationships between multimodal modes of brain structural variation and age, sex and polygenic scores for neuroticism in children and adolescents. Transl. Psychiatry 10, 251. https://doi.org/10.1038/s41398-020-00931-1.

Overbye, K., Huster, R.J., Walhovd, K.B., Fjell, A.M., Tamnes, C.K., 2018. Development of the P300 from childhood to adulthood: a multimodal EEG and MRI study. Brain Struct. Funct. 223, 4337-4349. https://doi.org/10.1007/s00429-018-1755-5.

Palomero-Gallagher, N., Zilles, K., 2019. Cortical layers: cyto-, myelo-, receptor- and synaptic architecture in human cortical areas. NeuroImage 197, 716-741. https:// doi.org/10.1016/j.neuroimage.2017.08.035. 
Panizzon, M.S., Fennema-Notestine, C., Eyler, L.T., Jernigan, T.L., Prom-Wormley, E., Neale, M., Jacobson, K., Lyons, M.J., Grant, M.D., Franz, C.E., Xian, H., Tsuang, M., Fischl, B., Seidman, L., Dale, A., Kremen, W.S., 2009. Distinct Genetic Influences on Cortical Surface Area and Cortical Thickness. Cereb. Cortex 19, 2728-2735. https:// doi.org/10.1093/cercor/bhp026.

Panizzon, M.S., Fennema-Notestine, C., Kubarych, T.S., Chen, C.-H., Eyler, L.T., Fischl, B., Franz, C.E., Grant, M.D., Hamza, S., Jak, A., Jernigan, T.L., Lyons, M.J., Neale, M.C., Prom-Wormley, E.C., Seidman, L., Tsuang, M.T., Wu, H., Xian, H., Dale, A.M., Kremen, W.S., 2012. Genetic and environmental influences of white and gray matter signal contrast: A new phenotype for imaging genetics? NeuroImage 60, 1686-1695. https://doi.org/10.1016/j.neuroimage.2012.01.122.

Paolicelli, R.C., Bolasco, G., Pagani, F., Maggi, L., Scianni, M., Panzanelli, P., Giustetto, M., Ferreira, T.A., Guiducci, E., Dumas, L., Ragozzino, D., Gross, C.T. 2011. Synaptic pruning by microglia is necessary for normal brain development. Science 333, 1456-1458. https://doi.org/10.1126/science.1202529.

Paquola, C., Bethlehem, R.A., Seidlitz, J., Wagstyl, K., Romero-Garcia, R., Whitaker, K.J. Vos de Wael, R., Williams, G.B., NSPN Consortium, Vértes, P.E., Margulies, D.S., Bernhardt, B., Bullmore, E.T., 2019. Shifts in myeloarchitecture characterise adolescent development of cortical gradients. eLife 8, e50482. https://doi.org/ 10.7554/eLife.50482.

Parker, N., Wong, A.P.-Y., Leonard, G., Perron, M., Pike, B., Richer, L., Veillette, S., Pausova, Z., Paus, T., 2017. Income inequality, gene expression, and brain maturation during adolescence. Sci. Rep. 7, 7397. https://doi.org/10.1038/s41598 017-07735-2.

Parker, N., Patel, Y., Jackowski, A.P., Pan, P.M., Salum, G.A., Pausova, Z., Paus, T., Saguenay Youth Study and the IMAGEN Consortium, 2020a. Assessment of neurobiological mechanisms of cortical thinning during childhood and adolescence and their implications for psychiatric disorders. JAMA Psychiatry 77, 1127. https:// doi.org/10.1001/jamapsychiatry.2020.1495.

Parker, N., Vidal-Pineiro, D., French, L., Shin, J., Adams, H.H.H., Brodaty, H., Cox, S.R., Deary, I.J., Fjell, A.M., Frenzel, S., Grabe, H., Hosten, N., Ikram, M.A., Jiang, J., Knol, M.J., Mazoyer, B., Mishra, A., Sachdev, P.S., Salum, G., Satizabal, C.L., Schmidt, H., Schmidt, R., Seshadri, S., Schumann, G., Völzke, H., Walhovd, K.B. Wen, W., Wittfeld, K., Yang, Q., Debette, S., Pausova, Z., Paus, T., 2020b. Corticosteroids and regional variations in thickness of the human cerebral cortex across the lifespan. Cereb. Cortex 30, 575-586. https://doi.org/10.1093/cercor/ bhz108.

Patel, Y., Shin, J., Gowland, P.A., Pausova, Z., Paus, T., IMAGEN consortium, 2019. Maturation of the Human Cerebral Cortex During Adolescence: Myelin or Dendritic Arbor? Cereb. Cortex 29, 3351-3362. https://doi.org/10.1093/cercor/bhy204.

Patel, Y., Shin, J., Drakesmith, M., Evans, J., Pausova, Z., Paus, T., 2020. Virtual histology of multi-modal magnetic resonance imaging of cerebral cortex in young men. NeuroImage 218, 116968. https://doi.org/10.1016/j neuroimage.2020.116968.

Paulus, M.P., Thompson, W.K., 2019. The challenges and opportunities of small effects: the new normal in academic psychiatry. JAMA Psychiatry 76, 353. https://doi.org/ 10.1001/jamapsychiatry.2018.4540.

Paus, T., 2010. Sex differences in the human brain. Progress in Brain Research. Elsevier, pp. 13-28. https://doi.org/10.1016/B978-0-444-53630-3.00002-6.

Paus, T., Keshavan, M., Giedd, J.N., 2008. Why do many psychiatric disorders emerge during adolescence? Nat. Rev. Neurosci. 9, 947-957. https://doi.org/10.1038/ nrn2513.

Paus, T., Nawaz-Khan, I., Leonard, G., Perron, M., Pike, G.B., Pitiot, A., Richer, L., Susman, E., Veillette, S., Pausova, Z., 2010. Sexual dimorphism in the adolescent brain: role of testosterone and androgen receptor in global and local volumes of grey and white matter. Horm. Behav. 57, 63-75. https://doi.org/10.1016/j. yhbeh.2009.08.004.

Paus, T., Pesaresi, M., French, L., 2014. White matter as a transport system. Neuroscience 276, 117-125. https://doi.org/10.1016/j.neuroscience.2014.01.055.

Paus, T., Wong, A.P.-Y., Syme, C., Pausova, Z., 2017. Sex differences in the adolescent brain and body: Findings from the saguenay youth study: Sex Differences in Adolescent Brain and Body. J. Neurosci. Res. 95, 362-370. https://doi.org/10.1002 jnr. 23825 .

Pecheva, D., Lee, A., Poh, J.S., Chong, Y.-S., Shek, L.P., Gluckman, P.D., Meaney, M.J., Fortier, M.V., Qiu, A., 2020. Neural transcription correlates of multimodal cortical phenotypes during development. Cereb. Cortex 30, 2740-2754. https://doi.org/ 10.1093/cercor/bhz271.

Pelvig, D.P., Pakkenberg, H., Stark, A.K., Pakkenberg, B., 2008. Neocortical glial cell numbers in human brains. Neurobiol. Aging 29, 1754-1762. https://doi.org/ 10.1016/j.neurobiolaging.2007.04.013.

Peper, J.S., Dahl, R.E., 2013. The Teenage Brain: Surging Hormones-Brain-Behavior Interactions During Puberty. Curr. Dir. Psychol. Sci. 22, 134-139. https://doi.org/ 10.1177/0963721412473755.

Peper, J.S., Hulshoff Pol, H.E., Crone, E.A., van Honk, J., 2011. Sex steroids and brain structure in pubertal boys and girls: a mini-review of neuroimaging studies. Neuroscience 191, 28-37. https://doi.org/10.1016/j.neuroscience.2011.02.014.

Petanjek, Z., Judas, M., Kostovic, I., Uylings, H.B.M., 2008. Lifespan alterations of basal dendritic trees of pyramidal neurons in the human prefrontal cortex: a layer-specific pattern. Cereb. Cortex 18, 915-929. https://doi.org/10.1093/cercor/bhm124.

Petanjek, Z., Judaš, M., Šimić, G., Rašin, M.R., Uylings, H.B.M., Rakic, P., Kostović, I., 2011. Extraordinary neoteny of synaptic spines in the human prefrontal cortex. Proc. Natl. Acad. Sci. 108, 13281-13286. https://doi.org/10.1073/pnas.1105108108.

Piaget, J., Cook, M., 1952. The Origins of Intelligence in Children. International Universities Press, New York.
Pike, G.B., 1996. Pulsed magnetization transfer contrast in gradient echo imaging: a twopool analytic description of signal response. Magn. Reson. Med. 36, 95-103. https:// doi.org/10.1002/mrm.1910360117.

Qu, Y., Jorgensen, N.A., Telzer, E.H., 2021. A call for greater attention to culture in the study of brain and development. Perspect. Psychol. Sci. 16, 275-293. https://doi. org/10.1177/1745691620931461.

Rakic, P., 1988. Specification of cerebral cortical areas. Science 241, 170-176. https:// doi.org/10.1126/science.3291116.

Rakic, P., 1995. A small step for the cell, a giant leap for mankind: a hypothesis of neocortical expansion during evolution. Trends Neurosci. 18, 383-388. https://doi. org/10.1016/0166-2236(95)93934-P.

Rakic, P., 2009. Evolution of the neocortex: a perspective from developmental biology. Nat. Rev. Neurosci. 10, 724-735. https://doi.org/10.1038/nrn2719.

Rakic, P., Bourgeois, J.-P., Goldman-Rakic, P.S., 1994. Synaptic development of the cerebral cortex: implications for learning, memory, and mental illness. Progress in Brain Research. Elsevier, pp. 227-243. https://doi.org/10.1016/S0079-6123(08) 60543-9.

Raz, N., Millman, D., Sarpel, G., 1990. Cerebral correlates of cognitive aging: gray-whitematter differentiation in the medial temporal lobes, and fluid versus crystallized abilities. Psychobiology 18, 475-481.

Raznahan, Armin, Lerch, J.P., Lee, N., Greenstein, D., Wallace, G.L., Stockman, M., Clasen, L., Shaw, P.W., Giedd, J.N., 2011a. Patterns of coordinated anatomical change in human cortical development: a longitudinal neuroimaging study of maturational coupling. Neuron 72, 873-884. https://doi.org/10.1016/j. neuron.2011.09.028.

Raznahan, A., Shaw, P., Lalonde, F., Stockman, M., Wallace, G.L., Greenstein, D., Clasen, L., Gogtay, N., Giedd, J.N., 2011b. How Does Your Cortex Grow? J. Neurosci. 31, 7174-7177. https://doi.org/10.1523/JNEUROSCI.0054-11.2011.

Reardon, P.K., Seidlitz, J., Vandekar, S., Liu, S., Patel, R., Park, M.T.M., AlexanderBloch, A., Clasen, L.S., Blumenthal, J.D., Lalonde, F.M., Giedd, J.N., Gur, R.C., Gur, R.E., Lerch, J.P., Chakravarty, M.M., Satterthwaite, T.D., Shinohara, R.T., Raznahan, A., 2018. Normative brain size variation and brain shape diversity in humans. Science 360, 1222-1227. https://doi.org/10.1126/science.aar2578.

Reeves, C., Tachrount, M., Thomas, D., Michalak, Z., Liu, J., Ellis, M., Diehl, B. Miserocchi, A., McEvoy, A.W., Eriksson, S., Yousry, T., Thom, M., 2016. Combined Ex Vivo9.4 T MRI and Quantitative Histopathological Study in Normal and Pathological Neocortical Resections in Focal Epilepsy. Brain Pathol. 26, 319-333. https://doi.org/10.1111/bpa.12298.

Righart, R., Biberacher, V., Jonkman, L.E., Klaver, R., Schmidt, P., Buck, D., Berthele, A., Kirschke, J.S., Zimmer, C., Hemmer, B., Geurts, J.J.G., Mühlau, M., 2017. Cortical pathology in multiple sclerosis detected by the T1/T2-weighted ratio from routine magnetic resonance imaging: cortical Pathology in MS. Ann. Neurol. 82, 519-529. https://doi.org/10.1002/ana.25020.

Rimol, L.M., Nesvåg, R., Hagler, D.J., Bergmann, Ø., Fennema-Notestine, C., Hartberg, C. B., Haukvik, U.K., Lange, E., Pung, C.J., Server, A., Melle, I., Andreassen, O.A., Agartz, I., Dale, A.M., 2012. Cortical volume, surface area, and thickness in schizophrenia and bipolar disorder. Biol. Psychiatry 71, 552-560. https://doi.org/ 10.1016/j.biopsych.2011.11.026.

Ritchie, J., Pantazatos, S.P., French, L., 2018a. Transcriptomic characterization of MRI contrast with focus on the T1-w/T2-w ratio in the cerebral cortex. NeuroImage 174, 504-517. https://doi.org/10.1016/j.neuroimage. 2018.03.027.

Ritchie, S.J., Cox, S.R., Shen, X., Lombardo, M.V., Reus, L.M., Alloza, C., Harris, M.A., Alderson, H.L., Hunter, S., Neilson, E., Liewald, D.C.M., Auyeung, B., Whalley, H.C., Lawrie, S.M., Gale, C.R., Bastin, M.E., McIntosh, A.M., Deary, I.J., 2018b. Sex differences in the adult human brain: evidence from 5216 UK biobank participants. Cereb. Cortex 28, 2959-2975. https://doi.org/10.1093/cercor/bhy109.

Rochat, P., 2003. Five levels of self-awareness as they unfold early in life. Conscious. Cogn. 12, 717-731. https://doi.org/10.1016/s1053-8100(03)00081-3.

Rockland, K.S., 2015. About connections. Front. Neuroanat. 9 https://doi.org/10.3389/ fnana.2015.00061.

Rosen, A.F.G., Roalf, D.R., Ruparel, K., Blake, J., Seelaus, K., Villa, L.P., Ciric, R., Cook, P. A., Davatzikos, C., Elliott, M.A., Garcia de La Garza, A., Gennatas, E.D. Quarmley, M., Schmitt, J.E., Shinohara, R.T., Tisdall, M.D., Craddock, R.C., Gur, R. E., Gur, R.C., Satterthwaite, T.D., 2018. Quantitative assessment of structural image quality. NeuroImage 169, 407-418. https://doi.org/10.1016/j. neuroimage.2017.12.059.

Salat, D.H., Lee, S.Y., van der Kouwe, A.J., Greve, D.N., Fischl, B., Rosas, H.D., 2009. Age-associated alterations in cortical gray and white matter signal intensity and gray to white matter contrast. NeuroImage 48, 21-28. https://doi.org/10.1016/j. neuroimage.2009.06.074.

Schaer, M., Cuadra, M.B., Tamarit, L., Lazeyras, F., Eliez, S., Thiran, J.-P., 2008. A surface-based approach to quantify local cortical gyrification. IEEE Trans. Med. Imaging 27, 161-170. https://doi.org/10.1109/TMI.2007.903576.

Schaer, M., Cuadra, M.B., Schmansky, N., Fischl, B., Thiran, J.-P., Eliez, S., 2012. How to measure cortical folding from MR images: a step-by-Step tutorial to compute local gyrification index. J. Vis. Exp. 3417. https://doi.org/10.3791/3417.

Schmaal, L., Hibar, D.P., Sämann, P.G., Hall, G.B., Baune, B.T., Jahanshad, N., Cheung, J. W., van Erp, T.G.M., Bos, D., Ikram, M.A., Vernooij, M.W., Niessen, W.J., Tiemeier, H., Hofman, A., Wittfeld, K., Grabe, H.J., Janowitz, D., Bülow, R. Selonke, M., Völzke, H., Grotegerd, D., Dannlowski, U., Arolt, V., Opel, N., Heindel, W., Kugel, H., Hoehn, D., Czisch, M., Couvy-Duchesne, B., Rentería, M.E., Strike, L.T., Wright, M.J., Mills, N.T., de Zubicaray, G.I., McMahon, K.L., Medland, S. E., Martin, N.G., Gillespie, N.A., Goya-Maldonado, R., Gruber, O., Krämer, B., Hatton, S.N., Lagopoulos, J., Hickie, I.B., Frodl, T., Carballedo, A., Frey, E.M., van Velzen, L.S., Penninx, B.W.J.H., van Tol, M.-J., van der Wee, N.J., Davey, C.G., Harrison, B.J., Mwangi, B., Cao, B., Soares, J.C., Veer, I.M., Walter, H., Schoepf, D., 
Zurowski, B., Konrad, C., Schramm, E., Normann, C., Schnell, K., Sacchet, M.D., Gotlib, I.H., MacQueen, G.M., Godlewska, B.R., Nickson, T., McIntosh, A.M., Papmeyer, M., Whalley, H.C., Hall, J., Sussmann, J.E., Li, M., Walter, M., Aftanas, L., Brack, I., Bokhan, N.A., Thompson, P.M., Veltman, D.J., 2017. Cortical abnormalities in adults and adolescents with major depression based on brain scans from 20 cohorts worldwide in the ENIGMA Major Depressive Disorder Working Group. Mol. Psychiatry 22, 900-909. https://doi.org/10.1038/mp.2016.60.

Schnack, H.G., van Haren, N.E.M., Brouwer, R.M., Evans, A., Durston, S., Boomsma, D.I. Kahn, R.S., Hulshoff Pol, H.E., 2015. Changes in thickness and surface area of the human cortex and their relationship with intelligence. Cereb. Cortex 25, 1608-1617. https://doi.org/10.1093/cercor/bht357.

Schwartz, D.H., Dickie, E., Pangelinan, M.M., Leonard, G., Perron, M., Pike, G.B., Richer, L., Veillette, S., Pausova, Z., Paus, T., 2014. Adiposity is associated with structural properties of the adolescent brain. NeuroImage 103, 192-201. https://doi. org/10.1016/j.neuroimage.2014.09.030.

Sedmak, G., Judaš, M., 2021. White matter interstitial neurons in the adult human brain: $3 \%$ of cortical neurons in quest for recognition. Cells 10, 190. https://doi.org/ 10.3390/cells10010190.

Seldon, H.L., 2005. Does brain white matter growth expand the cortex like a balloon? Hypothesis and consequences. Laterality Asymmetries Body Brain Cogn. 10, 81-95. https://doi.org/10.1080/13576500342000310.

Seldon, H.L., 2007. Extended neocortical maturation time encompasses speciation, fatty acid and lateralization theories of the evolution of schizophrenia and creativity. Med. Hypotheses 69, 1085-1089. https://doi.org/10.1016/j.mehy.2007.03.001.

Shafee, R., Buckner, R.L., Fischl, B., 2015. Gray matter myelination of 1555 human brains using partial volume corrected MRI images. NeuroImage 105, 473-485. https://doi.org/10.1016/j.neuroimage.2014.10.054.

Shaw, P., Eckstrand, K., Sharp, W., Blumenthal, J., Lerch, J.P., Greenstein, D., Clasen, L., Evans, A., Giedd, J., Rapoport, J.L., 2007. Attention-deficit/hyperactivity disorder is characterized by a delay in cortical maturation. Proc. Natl. Acad. Sci. 104, 19649-19654. https://doi.org/10.1073/pnas.0707741104.

Shaw, P., Kabani, N.J., Lerch, J.P., Eckstrand, K., Lenroot, R., Gogtay, N., Greenstein, D. Clasen, L., Evans, A., Rapoport, J.L., Giedd, J.N., Wise, S.P., 2008. Neurodevelopmental trajectories of the human cerebral cortex. J. Neurosci. 28, 3586-3594. https://doi.org/10.1523/JNEUROSCI.5309-07.2008.

Sherman, L.E., Rudie, J.D., Pfeifer, J.H., Masten, C.L., McNealy, K., Dapretto, M., 2014 Development of the Default Mode and Central Executive Networks across early adolescence: a longitudinal study. Dev. Cogn. Neurosci. 10, 148-159. https://doi. org/10.1016/j.dcn.2014.08.002.

Shin, J., French, L., Xu, T., Leonard, G., Perron, M., Pike, G.B., Richer, L., Veillette, S., Pausova, Z., Paus, T., 2018. Cell-specific gene-expression profiles and cortical thickness in the human brain. Cereb. Cortex 28, 3267-3277. https://doi.org/ 10.1093/cercor/bhx197.

Silvers, J.A., McRae, K., Gabrieli, J.D.E., Gross, J.J., Remy, K.A., Ochsner, K.N., 2012. Age-related differences in emotional reactivity, regulation, and rejection sensitivity in adolescence. Emotion 12, 1235-1247. https://doi.org/10.1037/a0028297.

Sled, J.G., 2018. Modelling and interpretation of magnetization transfer imaging in the brain. NeuroImage 182, 128-135. https://doi.org/10.1016/j. neuroimage.2017.11.065.

Sommer, I.E.C., 2004. Do women really have more bilateral language representation than men? A meta-analysis of functional imaging studies. Brain 127, 1845-1852. https://doi.org/10.1093/brain/awh207.

Sowell, E.R., Thompson, P.M., Leonard, C.M., Welcome, S.E., Kan, E., Toga, A.W., 2004 Longitudinal mapping of cortical thickness and brain growth in normal children. J. Neurosci. 24, 8223-8231. https://doi.org/10.1523/JNEUROSCI.1798-04.2004.

Stanisz, G.J., Kecojevic, A., Bronskill, M.J., Henkelman, R.M., 1999. Characterizing white matter with magnetization transfer and T2. Magn. Reson. Med. 42, 1128-1136. https://doi.org/10.1002/(SICI)1522-2594(199912)42:6<1128::AID-MRM18>3.0 CO;2-9.

Steinberg, L., 2008. A social neuroscience perspective on adolescent risk-taking. Dev Rev. 28, 78-106. https://doi.org/10.1016/j.dr.2007.08.002.

Stüber, C., Morawski, M., Schäfer, A., Labadie, C., Wähnert, M., Leuze, C., Streicher, M., Barapatre, N., Reimann, K., Geyer, S., Spemann, D., Turner, R., 2014. Myelin and iron concentration in the human brain: a quantitative study of MRI contrast. NeuroImage 93, 95-106. https://doi.org/10.1016/j.neuroimage. 2014.02.026.

Subramanian, A., Tamayo, P., Mootha, V.K., Mukherjee, S., Ebert, B.L., Gillette, M.A., Paulovich, A., Pomeroy, S.L., Golub, T.R., Lander, E.S., Mesirov, J.P., 2005. Gene se enrichment analysis: a knowledge-based approach for interpreting genome-wide expression profiles. Proc. Natl. Acad. Sci. 102, 15545-15550. https://doi.org/ 10.1073/pnas.0506580102.

Tamnes, C.K., Østby, Y., Fjell, A.M., Westlye, L.T., Due-Tønnessen, P., Walhovd, K.B., 2010. Brain Maturation in Adolescence and Young Adulthood: Regional Age-Related Changes in Cortical Thickness and White Matter Volume and Microstructure. Cereb. Cortex 20, 534-548. https://doi.org/10.1093/cercor/bhp118.

Tamnes, C.K., Walhovd, K.B., Dale, A.M., Østby, Y., Grydeland, H., Richardson, G. Westlye, L.T., Roddey, J.C., Hagler, D.J., Due-Tønnessen, P., Holland, D., Fjell, A.M., 2013. Brain development and aging: overlapping and unique patterns of change. NeuroImage 68, 63-74. https://doi.org/10.1016/j.neuroimage.2012.11.039.

Tamnes, C.K., Herting, M.M., Goddings, A.-L., Meuwese, R., Blakemore, S.-J., Dahl, R.E. Güroğlu, B., Raznahan, A., Sowell, E.R., Crone, E.A., Mills, K.L., 2017. Development of the cerebral cortex across adolescence: a multisample study of inter-related longitudinal changes in cortical volume, surface area, and thickness. J. Neurosci. 37, 3402-3412. https://doi.org/10.1523/JNEUROSCI.3302-16.2017.

Thomason, M.E., 2020. Development of Brain Networks In Utero: Relevance for Common Neural Disorders. Biol. Psychiatry 88, 40-50. https://doi.org/10.1016/j. biopsych.2020.02.007.
Toro, R., Perron, M., Pike, B., Richer, L., Veillette, S., Pausova, Z., Paus, T., 2008. Brain size and folding of the human cerebral cortex. Cereb. Cortex 18, 2352-2357. https:// doi.org/10.1093/cercor/bhm261.

Uddin, Md.N., Figley, T.D., Solar, K.G., Shatil, A.S., Figley, C.R., 2019. Comparisons between multi-component myelin water fraction, T1w/T2w ratio, and diffusion tensor imaging measures in healthy human brain structures. Sci. Rep. 9, 2500. https://doi.org/10.1038/s41598-019-39199-x.

van der Meer, D., Frei, O., Kaufmann, T., Chen, C.-H., Thompson, W.K., O'Connell, K.S., Monereo Sánchez, J., Linden, D.E.J., Westlye, L.T., Dale, A.M., Andreassen, O.A., 2020. Quantifying the polygenic architecture of the human cerebral cortex: extensive genetic overlap between cortical thickness and surface area. Cereb. Cortex 30, 5597-5603. https://doi.org/10.1093/cercor/bhaa146.

Van Essen, D.C., 1997. A tension-based theory of morphogenesis and compact wiring in the central nervous system. Nature 385, 313-318. https://doi.org/10.1038/ $385313 \mathrm{a} 0$.

Vasung, L., Rollins, C.K., Velasco-Annis, C., Yun, H.J., Zhang, J., Warfield, S.K., Feldman, H.A., Gholipour, A., Grant, P.E., 2020. Spatiotemporal differences in the regional cortical plate and subplate volume growth during fetal development. Cereb. Cortex 30, 4438-4453. https://doi.org/10.1093/cercor/bhaa033.

Vidal-Pineiro, D., Parker, N., Shin, J., French, L., Grydeland, H., Jackowski, Ap., Mowinckel, Am., Patel, Y., Pausova, Z., Salum, G., Sørensen, Ø., Walhovd, K., Paus, T., Fjell, A., for the Alzheimer's Disease Neuroimaging Initiative, for the Australian Imaging Biomarkers, Lifestyle flagship study of ageing, 2020. Cellular correlates of cortical thinning throughout the lifespan. Sci. Rep. 10, 21803. https:// doi.org/10.1038/s41598-020-78471-3.

Vijayakumar, N., Allen, N.B., Youssef, G., Dennison, M., Yücel, M., Simmons, J.G., Whittle, S., 2016. Brain development during adolescence: A mixed-longitudinal investigation of cortical thickness, surface area, and volume: Brain Development During Adolescence. Hum. Brain Mapp. 37, 2027-2038. https://doi.org/10.1002/ hbm.23154.

Vijayakumar, N., Mills, K.L., Alexander-Bloch, A., Tamnes, C.K., Whittle, S., 2018. Structural brain development: a review of methodological approaches and best practices. Dev. Cogn. Neurosci. 33, 129-148. https://doi.org/10.1016/j. dcn.2017.11.008.

Vosberg, D.E., Syme, C., Parker, N., Richer, L., Pausova, Z., Paus, T., 2020. Sex continuum in the brain and body during adolescence and psychological traits. Nat. Hum. Behav. https://doi.org/10.1038/s41562-020-00968-8.

Vuoksimaa, E., Panizzon, M.S., Chen, C.-H., Fiecas, M., Eyler, L.T., FennemaNotestine, C., Hagler, D.J., Franz, C.E., Jak, A.J., Lyons, M.J., Neale, M.C., Rinker, D. A., Thompson, W.K., Tsuang, M.T., Dale, A.M., Kremen, W.S., 2016. Is bigger always better? The importance of cortical configuration with respect to cognitive ability. NeuroImage 129, 356-366. https://doi.org/10.1016/j.neuroimage.2016.01.049.

Wake, H., Lee, P.R., Fields, R.D., 2011. Control of local protein synthesis and initial events in myelination by action potentials. Science 333, 1647-1651. https://doi. org/10.1126/science.1206998.

Walhovd, K.B., Tamnes, C.K., Fjell, A.M., 2014. Brain structural maturation and the foundations of cognitive behavioral development. Curr. Opin. Neurol. 27, 176-184. https://doi.org/10.1097/WCO.0000000000000074.

Walhovd, K.B., Tamnes, C.K., Bjornerud, A., Due-Tonnessen, P., Holland, D., Dale, A.M., Fjell, A.M., 2015. Maturation of cortico-subcortical structural networks-Segregation and overlap of medial temporal and fronto-striatal systems in development. Cereb. Cortex 25, 1835-1841. https://doi.org/10.1093/cercor/bht424.

Walhovd, K.B., Fjell, A.M., Giedd, J., Dale, A.M., Brown, T.T., 2016a. Through thick and thin: a need to reconcile contradictory results on trajectories in human cortical development. Cereb. Cortex. https://doi.org/10.1093/cercor/bhv301 bhv301.

Walhovd, K.B., Krogsrud, S.K., Amlien, I.K., Bartsch, H., Bjørnerud, A., DueTønnessen, P., Grydeland, H., Hagler, D.J., Håberg, A.K., Kremen, W.S., Ferschmann, L., Nyberg, L., Panizzon, M.S., Rohani, D.A., Skranes, J., Storsve, A.B., Sølsnes, A.E., Tamnes, C.K., Thompson, W.K., Reuter, C., Dale, A.M., Fjell, A.M., 2016b. Neurodevelopmental origins of lifespan changes in brain and cognition. Proc. Natl. Acad. Sci. 113, 9357-9362. https://doi.org/10.1073/pnas.1524259113.

Wang, F., Lian, C., Wu, Z., Zhang, H., Li, T., Meng, Y., Wang, L., Lin, W., Shen, D., Li, G., 2019. Developmental topography of cortical thickness during infancy. Proc. Natl. Acad. Sci. 116, 15855-15860. https://doi.org/10.1073/pnas.1821523116.

Westlye, L.T., Walhovd, K.B., Dale, A.M., Bjørnerud, A., Due-Tønnessen, P., Engvig, A., Grydeland, H., Tamnes, C.K., Østby, Y., Fjell, A.M., 2010. Differentiating maturational and aging-related changes of the cerebral cortex by use of thickness and signal intensity. NeuroImage 52, 172-185. https://doi.org/10.1016/j. neuroimage. 2010.03.056.

Whitaker, K.J., Vértes, P.E., Romero-Garcia, R., Váša, F., Moutoussis, M., Prabhu, G., Weiskopf, N., Callaghan, M.F., Wagstyl, K., Rittman, T., Tait, R., Ooi, C., Suckling, J., Inkster, B., Fonagy, P., Dolan, R.J., Jones, P.B., Goodyer, I.M., the NSPN Consortium, Bullmore, E.T., 2016. Adolescence is associated with genomically patterned consolidation of the hubs of the human brain connectome. Proc. Natl. Acad. Sci. 113, 9105-9110. https://doi.org/10.1073/pnas.1601745113.

White, T., Su, S., Schmidt, M., Kao, C.-Y., Sapiro, G., 2010. The development of gyrification in childhood and adolescence. Brain Cogn. 72, 36-45. https://doi.org/ 10.1016/j.bandc.2009.10.009.

Wierenga, L.M., Langen, M., Oranje, B., Durston, S., 2014. Unique developmental trajectories of cortical thickness and surface area. NeuroImage 87, 120-126. https:// doi.org/10.1016/j.neuroimage.2013.11.010.

Wierenga, L.M., Sexton, J.A., Laake, P., Giedd, J.N., Tamnes, C.K., the Pediatric Imaging, Neurocognition, and Genetics Study, 2018. A key characteristic of sex differences in the developing brain: greater variability in brain structure of boys than girls. Cereb. Cortex 28, 2741-2751. https://doi.org/10.1093/cercor/bhx154. 
Wierenga, L.M., Doucet, G.E., Dima, D., Agartz, I., Aghajani, M., Akudjedu, T.N., AlbajesEizagirre, A., Alnæs, D., Alpert, K.I., Andreassen, O.A., Anticevic, A., Asherson, P., Banaschewski, T., Bargallo, N., Baumeister, S., Baur-Streubel, R., Bertolino, A., Bonvino, A., Boomsma, D.I., Borgwardt, S., Bourque, J., Braber, A., Brandeis, D., Breier, A., Brodaty, H., Brouwer, R.M., Buitelaar, J.K., Busatto, G.F., Calhoun, V.D., Canales-Rodríguez, E.J., Cannon, D.M., Caseras, X., Castellanos, F.X., ChaimAvancini, T.M., Ching, C.R., Clark, V.P., Conrod, P.J., Conzelmann, A., Crivello, F., Davey, C.G., Dickie, E.W., Ehrlich, S., Ent, D., Fisher, S.E., Fouche, J., Franke, B., Fuentes-Claramonte, P., Geus, E.J., Di Giorgio, A., Glahn, D.C., Gotlib, I.H., Grabe, H. J., Gruber, O., Gruner, P., Gur, R.E., Gur, R.C., Gurholt, T.P., Haan, L., Haatveit, B., Harrison, B.J., Hartman, C.A., Hatton, S.N., Heslenfeld, D.J., Heuvel, O.A., Hickie, I. B., Hoekstra, P.J., Hohmann, S., Holmes, A.J., Hoogman, M., Hosten, N., Howells, F. M., Hulshoff Pol, H.E., Huyser, C., Jahanshad, N., James, A.C., Jiang, J., Jönsson, E. G., Joska, J.A., Kalnin, A.J., Karolinska Schizophrenia Project (KaSP) Consortium, Klein, M., Koenders, L., Kolskår, K.K., Krämer, B., Kuntsi, J., Lagopoulos, J., Lazaro, L., Lebedeva, I.S., Lee, P.H., Lochner, C., Machielsen, M.W., Maingault, S., Martin, N.G., et al., 2020. Greater male than female variability in regional brain structure across the lifespan. Hum. Brain Mapp. https://doi.org/10.1002/ hbm.25204 hbm.25204.

Williamson, J.M., Lyons, D.A., 2018. Myelin Dynamics Throughout Life: An EverChanging Landscape? Front. Cell. Neurosci. 12, 424. https://doi.org/10.3389/ fncel.2018.00424.

Winkler, A.M., Kochunov, P., Blangero, J., Almasy, L., Zilles, K., Fox, P.T., Duggirala, R., Glahn, D.C., 2010. Cortical thickness or grey matter volume? The importance of selecting the phenotype for imaging genetics studies. NeuroImage 53, 1135-1146. https://doi.org/10.1016/j.neuroimage.2009.12.028.

Winkler, A.M., Sabuncu, M.R., Yeo, B.T.T., Fischl, B., Greve, D.N., Kochunov, P., Nichols, T.E., Blangero, J., Glahn, D.C., 2012. Measuring and comparing brain cortical surface area and other areal quantities. NeuroImage 61, 1428-1443. https:// doi.org/10.1016/j.neuroimage.2012.03.026.

Winkler, A.M., Greve, D.N., Bjuland, K.J., Nichols, T.E., Sabuncu, M.R., Håberg, A.K., Skranes, J., Rimol, L.M., 2018. Joint analysis of cortical area and thickness as a replacement for the analysis of the volume of the cerebral cortex. Cereb. Cortex 28, 738-749. https://doi.org/10.1093/cercor/bhx308.

Wong, A.P.-Y., French, L., Leonard, G., Perron, M., Pike, G.B., Richer, L., Veillette, S., Pausova, Z., Paus, T., 2018. Inter-regional variations in gene expression and agerelated cortical thinning in the adolescent brain. Cereb. Cortex 28, 1272-1281. https://doi.org/10.1093/cercor/bhx040.

Xu, G., Knutsen, A.K., Dikranian, K., Kroenke, C.D., Bayly, P.V., Taber, L.A., 2010. Axons pull on the brain, but tension does not drive cortical folding. J. Biomech. Eng. 132, 071013 https://doi.org/10.1115/1.4001683.
Yakovlev, P.A., Lecours, I.R., 1967. The myelogenetic cycle of regional maturation of the brain. In: Minkowski, A. (Ed.), Regional Development of the Brain in Early Life. Blackwell, Oxford.

Yeo, B.T.T., Krienen, F.M., Sepulcre, J., Sabuncu, M.R., Lashkari, D., Hollinshead, M., Roffman, J.L., Smoller, J.W., Zöllei, L., Polimeni, J.R., Fischl, B., Liu, H., Buckner, R. L., 2011. The organization of the human cerebral cortex estimated by intrinsic functional connectivity. J. Neurophysiol. 106, 1125-1165. https://doi.org/10.1152/ jn.00338.2011.

Yun, H.J., Vasung, L., Tarui, T., Rollins, C.K., Ortinau, C.M., Grant, P.E., Im, K., 2020 Temporal Patterns of Emergence and Spatial Distribution of Sulcal Pits During Fetal Life. Cereb. Cortex 30, 4257-4268. https://doi.org/10.1093/cercor/bhaa053.

Zeisel, A., Munoz-Manchado, A.B., Codeluppi, S., Lonnerberg, P., La Manno, G., Jureus, A., Marques, S., Munguba, H., He, L., Betsholtz, C., Rolny, C., CasteloBranco, G., Hjerling-Leffler, J., Linnarsson, S., 2015. Cell types in the mouse cortex and hippocampus revealed by single-cell RNA-seq. Science 347, 1138-1142. https:// doi.org/10.1126/science.aaa1934.

Zhang, Y., Chen, K., Sloan, S.A., Bennett, M.L., Scholze, A.R., O'Keeffe, S., Phatnani, H.P., Guarnieri, P., Caneda, C., Ruderisch, N., Deng, S., Liddelow, S.A., Zhang, C., Daneman, R., Maniatis, T., Barres, B.A., Wu, J.Q., 2014. An RNA-Sequencing transcriptome and splicing database of glia, neurons, and vascular cells of the cerebral cortex. J. Neurosci. 34, 11929-11947. https://doi.org/10.1523/ JNEUROSCI.1860-14.2014.

Zhao, T., Liao, X., Fonov, V.S., Wang, Q., Men, W., Wang, Y., Qin, S., Tan, S., Gao, J.-H., Evans, A., Tao, S., Dong, Q., He, Y., 2019. Unbiased age-specific structural brain atlases for Chinese pediatric population. NeuroImage 189, 55-70. https://doi.org/ 10.1016/j.neuroimage.2019.01.006.

Zhou, D., Lebel, C., Treit, S., Evans, A., Beaulieu, C., 2015. Accelerated longitudinal cortical thinning in adolescence. NeuroImage 104, 138-145. https://doi.org/ 10.1016/j.neuroimage.2014.10.005.

Ziegler, G., Moutoussis, M., Hauser, T.U., Fearon, P., Bullmore, E.T., Goodyer, I.M., Fonagy, P., Jones, P.B., Lindenberger, U., Dolan, R.J., 2020. Childhood socioeconomic disadvantage predicts reduced myelin growth across adolescence and young adulthood. Hum. Brain Mapp. 41, 3392-3402. https://doi.org/10.1002/ hbm. 25024 .

Zilles, K., Armstrong, E., Schleicher, A., Kretschmann, H.-J., 1988. The human pattern of gyrification in the cerebral cortex. Anat. Embryol. (Berl.) 179, 173-179. https://doi. org/10.1007/BF00304699.

Zilles, K., Palomero-Gallagher, N., Amunts, K., 2013. Development of cortical folding during evolution and ontogeny. Trends Neurosci. 36, 275-284. https://doi.org/ 10.1016/j.tins.2013.01.006. 